\title{
Property changes in materials due to atomic oxygen in the low Earth orbit
}

\author{
Aki Goto $^{1}$ (D) $\cdot$ Kaori Umeda ${ }^{2} \cdot$ Kazuki Yukumatsu $^{1} \cdot$ Yugo Kimoto $^{1}$
}

Received: 16 November 2020 / Revised: 16 April 2021 / Accepted: 3 June 2021 / Published online: 28 June 2021

(c) The Author(s) 2021

\begin{abstract}
We expect satellites at altitude below $300 \mathrm{~km}$, very low Earth orbit (VLEO), making observations of the Earth at optical wavelength with increasingly higher resolution. The density of atomic oxygen (AO) at VLEO is significantly higher than that at LEO; severe degradation of spacecraft materials (polymers) due to the high-flux AO is a serious concern. To clarify VLEO environmental effects on spacecraft materials, we designed the Material Degradation Monitor (MDM) and MDM2 missions. The MDM is a material exposure experiment onboard the Super Low-Altitude Test Satellite (SLATS). It aims to understand reactions and degradation of polymeric materials depending on AO fluence in VLEO. In the MDM, samples of spacecraft material were exposed at altitude of $160-560 \mathrm{~km}$; their degradation behaviors were observed optically by a CCD camera for 1.8 years. The MDM2 is a material exposure experiment onboard the International Space Station (ISS) and aims to correctly understand surface reactions and degradation of the same samples used in the MDM at a given AO fluence. In the MDM2, the samples were exposed at altitude of $400 \mathrm{~km}$ for 1 year and then returned to Earth for analysis. Based on the results from both missions, we will help in the molecular design of more-durable materials, and establish design standards for future VLEO satellites. This study aims to quantitatively understand the surface reactions and degradation of the 11 types of thermal control materials exposed on the ISS in the MDM2. Five types of multilayer insulation (MLI) films (three types of Sicontaining AO protective materials (a silsesquioxane-( $S Q$-) containing coated polyimide film, two types of polysiloxane-block polyimide (BSF-30) films), an ITO-coated polyimide film, and a Beta Cloth), and flexible optical solar reflectors (flexible OSRs) were found to have a high durability against erosion by AO. This was determined by measuring their loss of mass and thermo-optical properties. The Ag/Inconel layer's discoloration and peeling were observed for three types of FEP/Ag films as determined by the Ag layer's oxidation by AO. Also, X-ray photoelectron spectroscopy (XPS) showed that reactions of the Si-containing materials, the $S Q$-coated polyimide film and the BSF-30 film, form a layer of silica that protects against AO. Even though the concentration of $\mathrm{Si}$ in the $S Q$-coating is the same or greater than in the BSF-30 film, the amount of the $S Q$-coating that reacted was larger than that of the BSF-30 film under the same AO fluence. Moreover, the effective ability of the UV-shielding coating, composed of ITO and $\mathrm{CeO}_{2}$ coated onto one of the BSF-30 films, was demonstrated by UV-Vis spectrometry. Its sufficient AO protection was confirmed by mass measurements, XPS analyses, and FE-SEM observations.
\end{abstract}

Keywords Atomic oxygen · Atomic-oxygen-resistant materials $\cdot$ Space exposure experiment $\cdot$ LEO $\cdot$ MDM2

\section{Introduction}

These days, we expect satellites at altitudes below $300 \mathrm{~km}$, in very low Earth orbit (VLEO), making observations of the

Aki Goto

goto.aki@jaxa.jp

1 Japan Aerospace Exploration Agency (JAXA), 2-1-1 Sengen, Tsukuba, Ibaraki 305-8505, Japan

2 Fundamental Technology Division, Advanced Engineering Services Co., Ltd., 1-6-1 Takezono, Tsukuba, Ibaraki 305-0032, Japan Earth at optical wavelengths with increasingly higher resolution $[1,2]$. To design VLEO satellites, an understanding of the effects of atomic oxygen (AO) on spacecraft materials is essential as materials that are more resistant to $\mathrm{AO}$ are needed. In space, various factors affect the performance of components and materials. These factors include residual atmosphere in low Earth orbit (LEO), highly energetic 
ultraviolet (UV) radiation from the Sun, high-energy ions, protons, and electrons. $\mathrm{AO}$ is an important constituent of the residual atmosphere between 200 and $700 \mathrm{~km}$ and is exceptionally hazardous to materials in LEO [3-5]. It collides with the polymers used in thermal control blankets at $8 \mathrm{~km} / \mathrm{s}$, which is the orbital velocity of a satellite. This corresponds to a translational energy of $5 \mathrm{eV}$. AO's collisions with such hyperthermal energy oxidize and erode polymer surfaces, degrading their thermo-optical and mechanical properties [6-8]. In particular, the AO density at VLEO levels is known to be at least ten times that between 500 and $700 \mathrm{~km} \mathrm{[5],}$ causing severe polymer degradation due to the high AO flux. This is a serious concern.

Numerous studies have reported the reaction processes of polymers in an $\mathrm{AO}$ environment through ground-based experiments [3, 9-11]. Here is a summary of their results. Initially, incident $\mathrm{AO}$ abstracts hydrogen atoms in polymers, forming $\mathrm{OH}$ radicals, volatile $\mathrm{OH}$, and $\mathrm{H}_{2} \mathrm{O}$ [9]. The radical sites are susceptible to further reactions with $\mathrm{AO}$; after hydrogen abstraction, the surface continuously generates volatile carbon-containing products such as $\mathrm{CO}$ and $\mathrm{CO}_{2}$ [10]. It is this continuous removal of carbon atoms that erodes polymers as measured by mass loss. These reaction processes probably occur in VLEO, but it is unknown whether the high AO flux causes any nonlinear processes. Furthermore, during the steady-state removal of carbon, there are collisions with molecular nitrogen $\left(\mathrm{N}_{2}\right)$ having a hyperthermal energy that enhances the rate of erosion [11]. In VLEO, the molecular nitrogen concentration is 10-30\%, which is not negligible [5]. To better understand VLEO environmental influences on materials, it is important to consider nonlinear processes due to high-flux $\mathrm{AO}$ and synergetic effects of $\mathrm{AO}$ and molecular nitrogen. However, it is difficult to reproduce the mixed environment of high-flux $\mathrm{AO}$ and molecular nitrogen in an experimental apparatus on Earth. In addition, the reaction characteristics of a polymer with $\mathrm{AO}$ depend on the chemical properties of the polymer; these include erosion yield and influences on thermo-optical and mechanical properties. Therefore, to ensure that polymers with sufficient durability are developed, it is necessary to study each polymer's reactions and degradation in a VLEO environment.

To clarify VLEO environmental effects on spacecraft materials and establish protective methods, we designed the Material Degradation Monitor (MDM) $[12,13]$ and the Material Degradation Monitor 2 (MDM2) missions [14, 15]. MDM is a material exposure experiment onboard the Super Low-Altitude Test Satellite (SLATS, or TSUBAME) developed by JAXA. It aims to understand the reactions and degradation of polymeric materials depending on $\mathrm{AO}$ fluence in VLEO altitudes. In the MDM, 13 samples of spacecraft material were exposed at an altitude of $160-560 \mathrm{~km}$ (including a VLEO altitude); their degradation behaviors were observed optically once a week by a CCD camera from February 21, 2018 to October 1, 2019. The AO fluence was also calculated by measuring frequency changes of a thermoelectric quartz crystal microbalance sensor coated with polyimide as well as observing erosion of a piece of bulk polyimide. Thus, we obtained degradation data for the samples as their optical property changes with polyimideequivalent AO fluence. According to atmospheric models such as NRL-MSISE00 [5], molecular nitrogen effects on the samples will also be discussed.

MDM2 is a material exposure experiment onboard the International Space Station (ISS) that uses the Exposed Experiment Handrail Attachment Mechanism (ExHAM) developed by JAXA [16]. MDM2 aims to correctly understand surface reactions and degradation of the same samples used in the MDM at a given AO fluence. In the MDM2, 16 samples of spacecraft material were exposed at an altitude of $400 \mathrm{~km}$ from May 26, 2015 to June 13, 2016 then returned for analysis. The AO fluence was measured using a piece of bulk polyimide. Note that the MDM2 mission could not obtain data on material degradation as the MDM mission did in VLEO. The fraction of molecular nitrogen at altitude of $400 \mathrm{~km}$ is extremely low [5]; therefore, neither higher flux AO nor molecular nitrogen effects could be detected in the MDM2. However, the MDM2 had the advantage that the samples could be analyzed in detail after their return. It supported interpreting their optical changes in the MDM by identifying reactions and degradation only by AO and UV. The results from both missions will help in the molecular design of more-durable materials and establish design standards for future VLEO satellites.

The samples exposed in the MDM and MDM2 missions were almost the same; these materials are expected to be used in future VLEO satellites. They included bulk polyimide for AO monitoring, 11 types of thermal control films, and four types of cables. Significantly, the thermal control films included three types of silicon ( $\mathrm{Si}$ )-containing materials developed by JAXA for their durability against AO: a polyimide film coated with a silsesquioxane-containing coating ( $S Q$-coated polyimide film), a polysiloxane-blockpolyimide film (BSF-30 film), and a polysiloxane-block-polyimide film coated with a UV-shielded coating (UV-shielded BSF-30 film).

This study aims to quantitatively understand the surface reactions and degradation of the 11 types of thermal control materials exposed on the ISS in the MDM2. The AO fluence during exposure was estimated by measuring the mass loss and erosion depth of the bulk polyimide. The mass loss and thermo-optical property changes were measured to determine the extent of the reactions and degradation. The surface changes in the chemical structure and morphology of the three Si-containing materials above were analyzed by $\mathrm{X}$-ray photoelectron spectroscopy (XPS) and field-emission 
scanning electron microscope (FE-SEM). This article provides data on the degradation of the eleven types of thermal control materials and the results of surface analyses of the three types of Si-containing materials. This paper also discusses their reaction characteristics from being exposed to an LEO environment for 1 year.

\section{MDM2 flight experiment and analysis methods}

\subsection{Material samples}

Table 1 lists the sample materials and their applications on spacecraft. Figure 1 shows a photograph of a sample holder and the positions of the mounted samples [14]. These samples include a material for AO monitoring, thermal control films used in multilayer insulations (MLIs) and optical solar reflectors (OSRs), and cables.
Table 1 Material samples exposed in the MDM2 mission

\begin{tabular}{|c|c|c|}
\hline Installed position & Material sample & Application \\
\hline 1 & Vespel & Atomic oxygen monitor \\
\hline 2 & $\begin{array}{l}\text { AO protective coating ( } S Q \text {-coating)/polyimide film } \\
\left.\text { (Upilex-R)/Al }{ }^{\mathrm{a}}\right)\end{array}$ & MLI \\
\hline 3 & AO protective polyimide film (BSF-30)/Al & \\
\hline 4 & $\begin{array}{l}\text { UV-shielding coating }\left(\mathrm{ITO}, \mathrm{CeO}_{2}\right) / \mathrm{AO} \text { protective } \\
\text { polyimide film }(\mathrm{BSF}-30) / \mathrm{Ag}\end{array}$ & \\
\hline 10 & ITO coating/polyimide film (Upilex-R)/Al ${ }^{\mathrm{a}}$ ) & \\
\hline 12 & Beta Cloth/Al ${ }^{\mathrm{b})}$ & \\
\hline 9 & $\operatorname{FEP}\left(1 \mathrm{mil}^{\mathrm{c})}\right)$ film/ $/ \mathrm{Ag}^{\mathrm{b})}$ & OSR \\
\hline 11 & $\operatorname{FEP}\left(5 \mathrm{mil}^{\mathrm{c})}\right)$ film/ $/ \mathrm{Ag}^{\mathrm{b})}$ & \\
\hline 13 & ITO coating/FEP $\left(5 \mathrm{mil}^{\mathrm{c})}\right)$ film/Ag ${ }^{\mathrm{a})}$ & \\
\hline $14,15,16$ & Flexible-OSR $1,2,3^{\mathrm{d}}$ & \\
\hline 5 & Expanded PTFE cable $(\phi 1.18 \mathrm{~mm})$ & Cable \\
\hline 6 & Expanded PTFE cable $(\phi 1.35 \mathrm{~mm})$ & \\
\hline 7 & Expanded PTFE cable $(\phi 1.58 \mathrm{~mm})$ & \\
\hline 8 & ETFE cable $(\phi 1.15 \mathrm{~mm})$ & \\
\hline
\end{tabular}

a) Coating (exposed face)/base film/coating (back face)

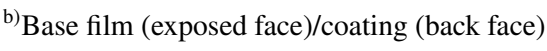

${ }^{\text {c) }}$ Thicknesses of the FEP films

d) The numbers 1-3 show the difference in manufacturing conditions to optimize the roll-to-roll process
Fig. 1 a Photograph of a sample holder before exposure and $\mathbf{b}$ the samples' positions (a)

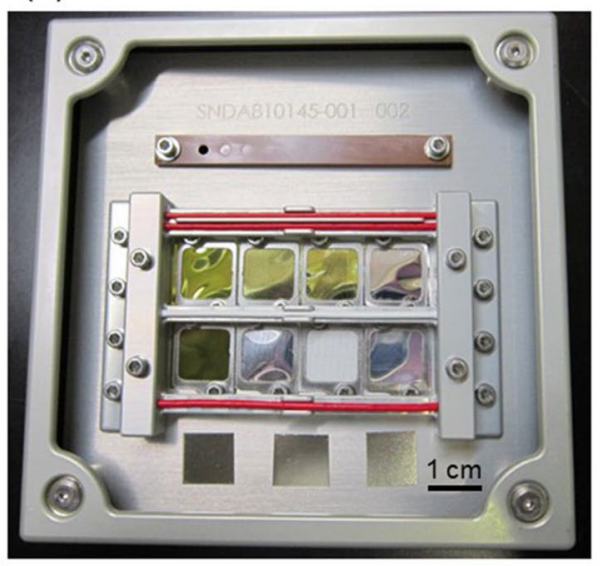

(b)

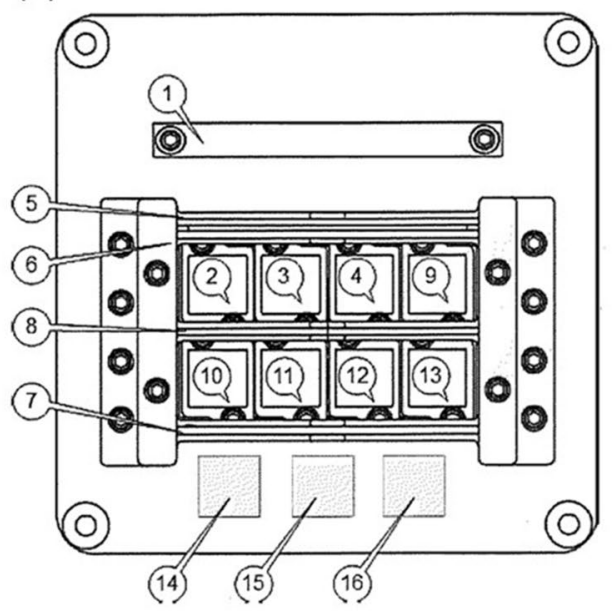


To monitor AO fluence during the exposure, a piece of Vespel (bulk polyimide, DuPont, Inc., position (1) was exposed. Its AO erosion yield is $2.94 \times 10^{-24} \mathrm{~cm}^{3} /$ atom [17]; this allows the AO fluence to be calculated from the mass loss of the sample. The Vespel sample was $6 \mathrm{~mm}$ high, $60 \mathrm{~mm}$ wide, and $2 \mathrm{~mm}$ thick; $3.21 \mathrm{~cm}^{2}$ of its surface was exposed. The Vespel had ten 2-mm-diameter cylindrical holes on its back surface as that used in the MDM on the SLATS [13]. The holes had different depths; one of them was originally penetrated. In the MDM, the Vespel could not be returned to Earth to measure its mass loss; therefore, the AO fluence was evaluated by detecting the timings when each hole was penetrated due to erosion, using a CCD camera. To match the exposed conditions with those in the MDM, the Vespel with holes was used in the MDM2, as well. In addition, we used Vespel to monitor the AO fluence in our previous experiments on the ISS (SM/MPAC\&SEED [18] and JEM/MPAC\&SEED [19]).

The three Si-containing materials JAXA developed to resist erosion by $\mathrm{AO}$ were exposed in the experiment to determine their reactions and durability. One was a polyimide film (Upilex-R, Ube Industries, Ltd., thickness $25 \mu \mathrm{m}$ ) coated with a silsesquioxane-containing coating ( $S Q$ coating, Toagosei Co., Ltd.) mounted on position (2) [20]. Silsesquioxane $\left(\mathrm{RSiO}_{3 / 2}\right)$ has an intermediate structure and properties of inorganic silica and organic silicone [21, 22]. Examples of the silsesquioxane derivatives composing the $S Q$-coating are shown in Fig. 2a [20]. They have various chemical structures such as random, cages, and each molecule has photocurable organic units (expressed as R) composed of acryloyl groups. In the coating process, the silsesquioxane monomers were coated and cured on the polyimide film (Upilex-R) via radical polymerization initiated by UV. The cured coating was $1.1 \mathrm{~mm}$ thick (measured by cross-sectional scanning transmission electron microscope observation). A previous study performed with a laser-detonation AO source has reported that the mass losses of the $S Q$-coated polyimide films were $0.4-0.5 \%$ those of uncoated polyimide films (Kapton H, Du Pont-Toray Co., Ltd.) [20]. In addition, the coating has been found by XPS to react with AO, forming a silica (silicon oxide) layer [23]. The high resistance of the $S Q$-coated polyimide film to $\mathrm{AO}$ is caused by the silica layer acting as a protective coating. Although such ground-based experiments had investigated its AO effects, its LEO and VLEO environmental effects have not been understood yet. This MDM2 was the first experiment to expose it in LEO.

The other two were polysiloxane-block-polyimide films (BSF-30, NIPPON STEEL Chemical \& Material Co., Ltd., thickness $25 \mu \mathrm{m}$ ) mounted at positions (3) and (4) [24-26].
Fig. 2 Chemical structures of a examples of silsesquioxane derivatives composing the $S Q$-coating (reprinted with permission from [20]) and $\mathbf{b}$ the BSF-30 film [26]. $\mathrm{X}$ and $\mathrm{Y}$ in $\mathbf{b}$ are confidential (a)
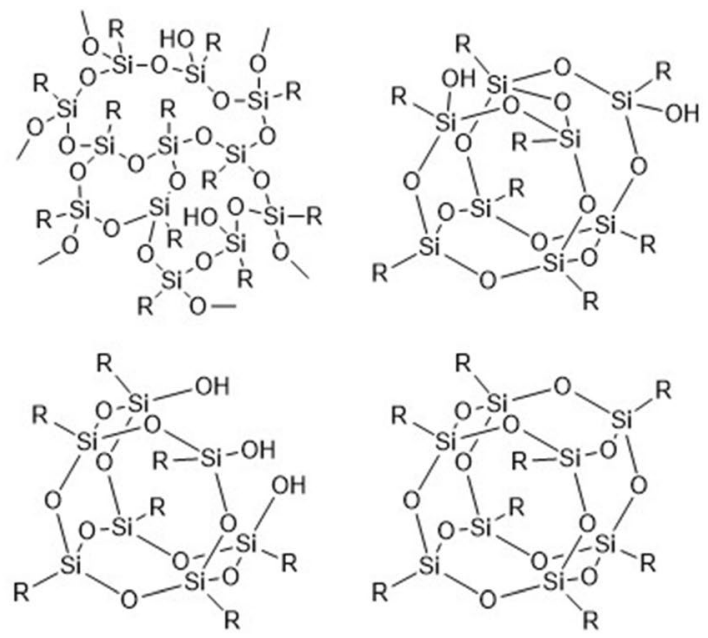

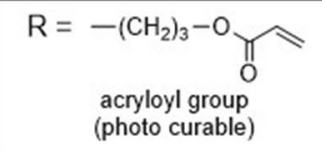

etc.

(b)

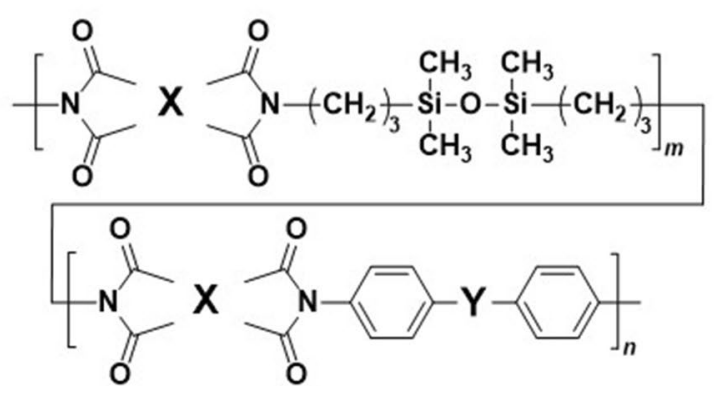


The chemical structure of polysiloxane-block-polyimide composing the BSF-30 film is shown in Fig. 2 b; its siloxane structure ( $\mathrm{Si}-\mathrm{O}-\mathrm{Si})$ is incorporated into its main chain [26]. In the previous studies using a laser-detonation AO source, mass losses of the BSF-30 film were not linear with AO fluence and 0.3-4\% those of a polyimide film (Kapton $\mathrm{H}$ [24] or PMDA-ODA (SP-510, Du Pont -Toray Co., Ltd.) [26]). And, in an LEO exposure study on the ISS, its mass loss was less than $0.2 \%$ that of a polyimide (Vespel) [25]. In terms of mass loss, the reaction extent in ground-based AO irradiation was suggested to be the same or more than that in LEO. In addition, the BSF-30 film has also been found by XPS to react with $\mathrm{AO}$, forming a silica layer [24-26]. In contrast to the results of mass loss, the thickness of the formed silica (i.e., the reaction extent) in ground-based $\mathrm{AO}$ irradiation $\left(5-10 \mathrm{~nm}\right.$ at AO fluence of $5.8 \times 10^{20}$ atoms $/ \mathrm{cm}^{2}$ ) was less than that in LEO $\left(50 \mathrm{~nm}\right.$ at $5.9 \times 10^{20}$ atoms $\left./ \mathrm{cm}^{2}\right)$ [25]. Its high resistance to $\mathrm{AO}$ is caused by the silica layer acting as a protective coating, but its detailed reaction extent has not been investigated in LEO or VLEO nor have the factors causing the inconsistency between ground-based irradiation and space exposure. Besides, in this MDM2, one of the BSF30 films was coated with a UV-shielding layer composed of indium tin oxide (ITO) and cerium oxide $\left(\mathrm{CeO}_{2}\right.$, position (4) on its surface. The silica-equivalent thickness of the UVshielding coating was $280 \mathrm{~nm}$, measured by XPS with an argon-(Ar-) ion etching as mentioned in Sect. 3.5. To better understand the utility of the UV-shielding layer, its durability against UV radiation was also evaluated.

There were also three types of silver-coated fluorinated ethylene propylene (FEP) films (Sheldahl, Inc., positions (9, (11), (13)). The thicknesses of the FEP film were $1 \mathrm{mil}(25 \mu \mathrm{m}$, position (9) and $5 \mathrm{mil}(127 \mu \mathrm{m}$, positions (11) and (13)), and one of them had an ITO layer on its exposed surface (position (13). They all have a 30-nm-thick Ni alloy (Inconel) layer and a 150-nm-thick silver layer on their back side. The thin Inconel layer is coated to prevent the silver layer from oxidizing. A recent ground-based study has reported that the erosion yield of FEP by Ar with hyperthermal energy (as an inert gas with a molecular weight roughly that of a nitrogen molecule) was higher than that of polyimide [27]. This result suggests that severe erosion of FEP can be caused by molecular nitrogen in VLEO. In the MDM, to investigate molecular nitrogen effects on FEP erosion, three types of silver-coated FEP films mentioned above were exposed. Here, in the MDM2, the AO and UV effects on their erosion were identified.

In addition, ITO-coated polyimide (Upilex-R, Ube Industries, Ltd., thickness $25 \mu \mathrm{m}$, position (10), Beta Cloth (fiberglass cloth coated with FEP, Sheldahl, Inc., thickness $100 \mathrm{~mm}$, position (12), and flexible OSRs (positions (14)-(16)) were exposed. Several studies of ITO-coated polyimide and the Beta Cloth have already reported their erosion yields and thermo-optical property changes due to AO and UV based on ground and flight experiments [28, 29]. Surface reactions and degradation of these materials observed in the MDM2 were compared to those obtained in the past studies. The flexible OSRs are polyetherimide (PEI)-based OSRs developed by JAXA, and are composed of five layers such as ITO, $\mathrm{CeO}_{2}$, PEI film (Mitsubishi Chemical Corp., thickness $100 \mu \mathrm{m}$ ), Ag alloy (APC), and Inconel [30]. Three expanded PTFE (polytetrafluoroethylene) cables (W. L. Gore \& Associates, Inc., positions (5- (7)), and an ETFE (ethylenetetrafluoroethylene) cable (TE Connectivity Ltd., position (8) were also exposed.

The flexible OSRs were attached to the sample holders by an acrylic adhesive with low outgassing properties (Y966, 3 M Company). Each thermal control film mounted on the holder was held in place by an aluminum plate secured with screws, and there was a hole in each plate to permit exposure. The Vespel and the cables were secured with screws. A square, $1 \mathrm{~cm}^{2}$ area of each thermal control film was exposed.

The samples exposed in the MDM2 were almost the same as those exposed in the MDM as mentioned below, but some of them were different. First, the base film of $S Q$-coated polyimide film exposed in the MDM was Apical-AH (Kaneka Corp., thickness $25 \mu \mathrm{m}$ ), not Upilex-R as in the MDM2, because only the $S Q$-coated Apical is expected to be commercialized. Second, the flexible OSRs were not exposed in the MDM because of space limitation. The other samples exposed in the MDM were the same as those exposed in the MDM2.

\subsection{Space exposure using the ExHAM installed on the ISS}

The MDM2 samples were launched to Kibo on April 15, 2015 by a Dragon SpX-6. The sample holder was mounted on the ram face (on toward the ISS velocity vector) of the ExHAM and installed on the Kibo Exposed Facility by a robot arm on May 26, 2015 (Fig. 3). The samples were oriented perpendicular to the direction of ISS flight, so they were exposed to a direct AO attack. The samples were exposed for about 1 year, from May 26, 2015 to June 13, 2016, and then returned by a Dragon SpX-9 on August 27, 2016.

\subsection{Measurement and analysis methods}

The thermo-optical properties such as UV-Vis-near-infrared (NIR) reflectance spectra, solar absorptances $\left(\alpha_{s}\right)$, and normal infrared emittance $\left(\varepsilon_{N}\right)$ of the samples were measured by a UV-Vis-NIR spectrometer with an integrating sphere (U-4100, Hitachi High-Tech Corp.) and a portable reflectometer (TESA 2000, AZ Technology, Inc.). The ranges of measured wavelength were $250-2500 \mathrm{~nm}$ for the reflectance 


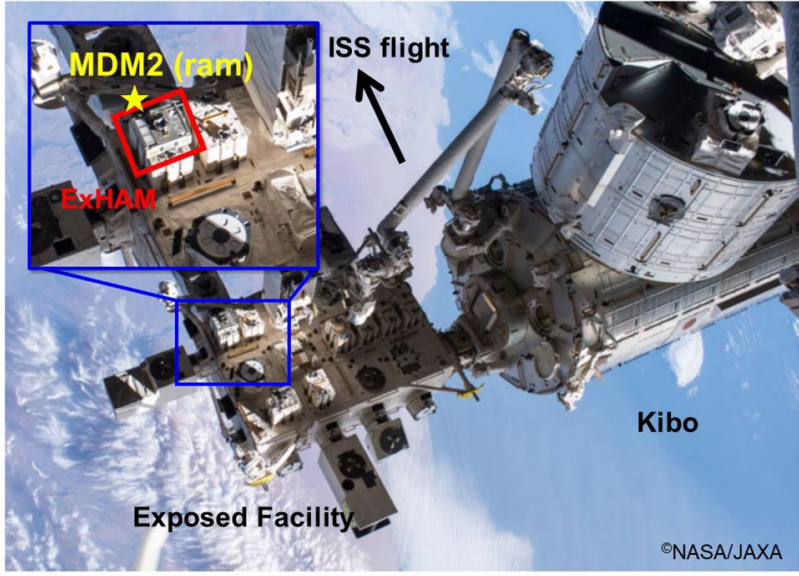

Fig. 3 Installed positions of the ExHAM and the MDM2 sample holder on the Kibo exposed facility. An arrow points in the direction of the ISS flight

spectra and $\alpha_{s}$, and 3-35 $\mu \mathrm{m}$ for $\varepsilon_{N^{*}}$. The $\alpha_{s}$ was calculated as shown in Eq. (1)

$\frac{\int_{250}^{2500}\left(1-\frac{\% R(\lambda)}{100}\right) S(\lambda) d \lambda}{\int_{250}^{2500} S(\lambda) d \lambda}$,

where $\% R(\lambda)$ is reflectance, $S(\lambda)$ is the intensity of solar irradiance at air mass zero in $\mathrm{mW} / \mathrm{cm}^{2} \mathrm{~nm}$ [31], and $d \lambda$ is wavelength interval in unit of $\mathrm{nm}$. The $\varepsilon_{N}$ was calculated as shown in Eq. (2)

$\varepsilon_{N}=1-\frac{\sigma T^{4}}{I}$,

where $\sigma$ is Stefan-Boltzmann constant $\left(5.67 \times 10^{-8} \mathrm{~W} /\right.$ $\left.\mathrm{m}^{2} \mathrm{~K}^{4}\right), T$ is the temperature of an infrared source $(300 \mathrm{~K})$, and $I$ is the energy of infrared reflection on a sample in $\mathrm{W} /$ $\mathrm{m}^{2}$.

The masses of the material samples were measured by an electronic microbalance (XP6, Mettler Toledo, Inc., minimum mass: $1 \mu \mathrm{g}$, repeatability: $0.8 \mu \mathrm{g}$ ). Before the mass measurements, the samples were dehydrated in a desiccator at $23 \pm 2{ }^{\circ} \mathrm{C}$ and $50 \pm 5 \%$ humidity for more than $6 \mathrm{~h}$. Mass was measured for $152 \mathrm{~s}$ after the dehydration; the dry mass value was calculated as the intercepts of quadratic fitted curves that express the correlation between the mass changes and the elapsed time, as shown in an example of Fig. 4. The erosion depth of the Vespel was measured by a laser microscope (OLS-4100, Olympus Corp.). The laser wavelength was $405 \mathrm{~nm}$.

The cross-sections of the silver-coated FEP films were observed by FE-SEM (Merlin, Carl Zeiss Co., Ltd.). The acceleration voltage was $0.8 \mathrm{kV}$. The cross-sectional samples were obtained by an ion beam milling system (EM

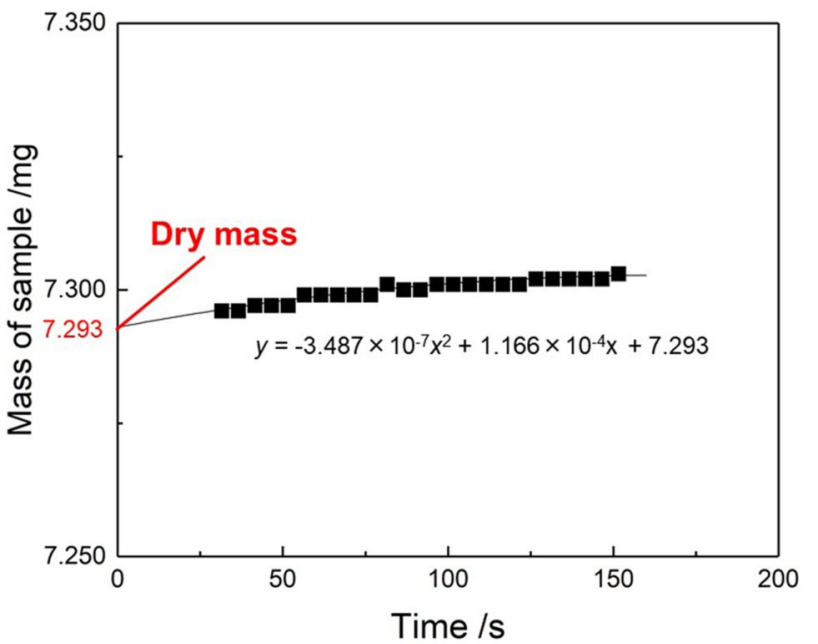

Fig. 4 Mass of an $S Q$-coated polyimide film (exposed in the MDM2) measured by an electronic microbalance as a function of elapsed time after being taken out from a desiccator. The dry mass value was defined as the intercept of the quadratic fitted curve (solid line)

TIC 3X, Leica Microsystems GmbH, argon (Ar) ion), and then thinly coated with $\mathrm{Pt}$ to prevent from charging in the observation. The $S Q$-coated polyimide film surfaces and the two BSF-30 films were also observed by FE-SEM (S4800, Hitachi High-Tech Corp.). The acceleration voltage was $5 \mathrm{kV}$; the tilt angle was $0^{\circ}$. The samples were thinly coated with Pt before the observations.

The $S Q$-coated polyimide film surfaces and the BSF30 films were also analyzed by XPS (K-Alpha, Thermo Scientific, Inc.). Al Ka (1486.6 eV) was used as the X-ray source. Depth profiles of the surface chemical composition were obtained with etching by a $2 \mathrm{keV}$ Ar-ion beam.

\section{Results and discussion}

\subsection{AO fluence}

To evaluate the number of AO collisions (AO fluence) on the samples during the exposure in the MDM2, the mass loss of the Vespel was measured by an electronic microbalance. Its mass loss was $2.83 \times 10^{-2} \mathrm{~g}$; the AO fluence $(F)$ was calculated to be $2.1 \times 10^{21}$ atoms $/ \mathrm{cm}^{2}$ according to this equation

$F=\frac{m}{\rho A E_{y}}$,

where $m$ is the mass loss of the Vespel, $\rho$ is its density $\left(1.43 \mathrm{~g} / \mathrm{cm}^{3}\right), A$ is its exposed area $\left(3.21 \mathrm{~cm}^{2}\right)$, and $E_{y}$ is its AO erosion yield $\left(2.94 \times 10^{-24} \mathrm{~cm}^{3} /\right.$ atom [17]). 
Also, the erosion depth $(d \mathrm{~cm})$ of the Vespel was measured by a laser microscope, because the AO fluence was calculated from the following equation [6]:

$F=\frac{d}{E_{y}}$.

Here, step height at three positions on the exposed surface (A-C in Fig. 5a) around two washers under the screw heads was considered the erosion depth. At these three positions, the step was observed, such that its top surface was wide and flat. Figure $5 \mathrm{~b}$ shows a laser microscope image of position A. The top of the step was flat because the area was shielded from AO by the washer. In contrast, the bottom of the step was rough, because it was eroded by $\mathrm{AO}$, causing the formation of cone-like microstructures $[3,6,8]$. To calculate the step height, the obtained 3D

(a)
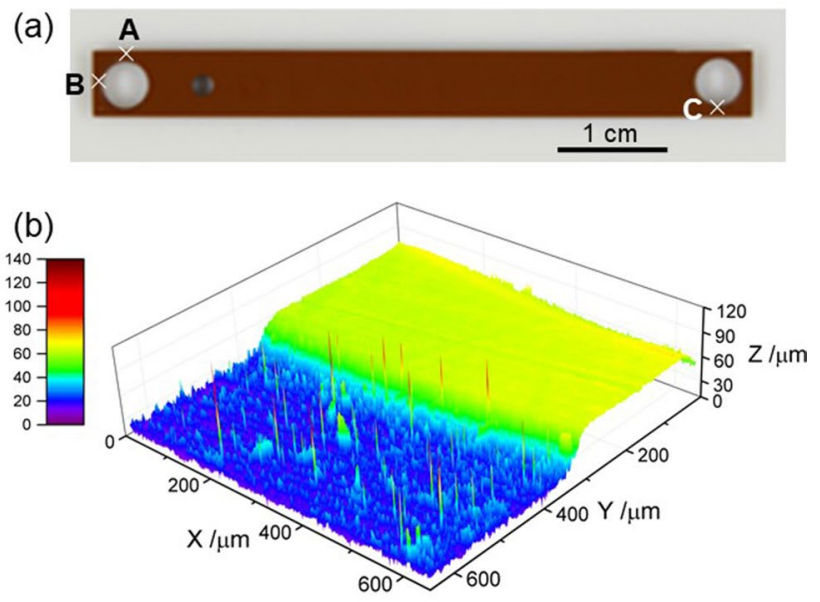

(c)

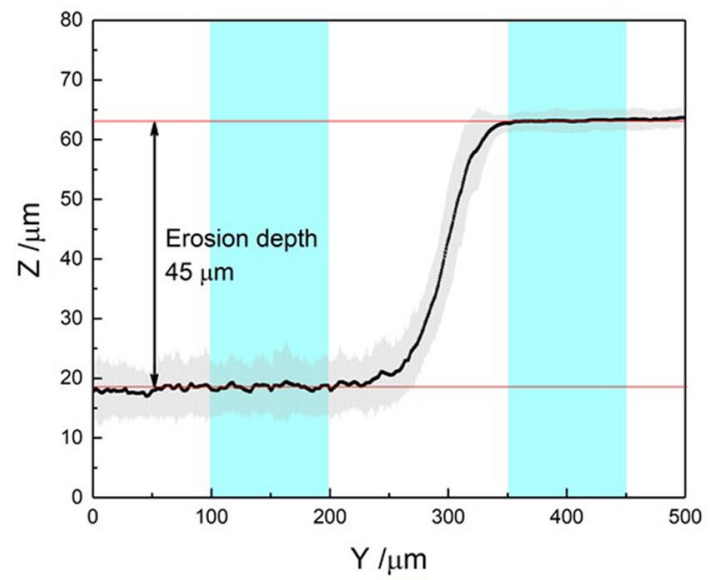

Fig. 5 a Positions A-C on the Vespel observed by a laser microscope, b laser microscope image (3D height profile) of the position $\mathrm{A}$, and $\mathbf{c}$ 2D height profile obtained by averaging the $3 \mathrm{D}$ height profile along the $X$ axis of the position A (solid line). Error bars (gray bars) in (c) show the standard deviation (S.D.) of the height profile. The average height profiles in cyan regions were used to calculate erosion depth height profile was averaged in the direction perpendicular to the step. For example, the 3D height profile of position A (Fig. 5b) was averaged along the $X$ axis; the 2D height profile was obtained, as shown in Fig. 5c. Then, the step height was calculated as the difference between the top and bottom heights on the 2D height profile. The top and bottom heights were defined as average heights at plateau regions with a width of $100 \mathrm{~mm}$ (such as cyan regions on the right and left sides in Fig. 5c). As a result, the step heights at A-C were calculated as 45,43 , and $38 \mu \mathrm{m}$ $\left(4.5 \times 10^{-3}, 4.3 \times 10^{-3}\right.$, and $\left.3.8 \times 10^{-3} \mathrm{~cm}\right)$; the AO fluences calculated by substituting them for the Eq. (4) were $1.3-1.5 \times 10^{21}$ atoms $/ \mathrm{cm}^{2}$. Note that these fluences calculated from the step heights showed variations, mainly due to the roughness of the exposed surface. Although relative uncertainties of the top heights of the step (calculated by dividing its average by its standard deviation [SD]) were only $1-3 \%$, those of the bottom heights were $20-30 \%$, as shown in error bars in the 2D height profile (Fig. 5c).

Considering such uncertainties as well, the AO fluence calculated from the step heights was 30-40\% lower than that calculated from the mass loss $\left(2.1 \times 10^{21}\right.$ atoms $\left./ \mathrm{cm}^{2}\right)$. A reason for this difference is that the mass loss of the Vespel includes the contribution of the erosion from its side faces. In this experiment, the front face of the Vespel and its side faces were exposed to space. The side faces were assumed to be eroded by AO, which has an angular distribution of arrival flux [2]. The area of the side faces was $2.64 \mathrm{~cm}^{2}$, comparable to that of the front face $\left(3.21 \mathrm{~cm}^{2}\right)$; therefore, the AO fluence calculated from the mass loss was probably overestimated due to the erosion from the side faces.

Besides, the AO fluence was also calculated by an NRLMSISE-00 (MSIS) atmospheric model [3] using a JAXA Space Environment \& Effects System (SEES) [32] to be $1.5 \times 10^{21}$ atoms $/ \mathrm{cm}^{2}$ in the period of May 26, 2015-June 13, 2016. In this calculation using the MSIS model and the JAXA SEES, orbital elements of the ISS were assumed (epoch: May 25, 2015 at 14:43, semimajor axis: $6779.8 \mathrm{~km}$, inclination: $51.645^{\circ}$, eccentricity: 0.00039 , right ascension of ascending node: $196.744^{\circ}$, argument of perigee: $342.982^{\circ}$, and mean anomaly: $176.385^{\circ}$ ). Zenith and azimuth angles of the exposed surface were assumed to be $90^{\circ}$ and $0^{\circ}$, respectively, to simulate AO colliding vertically. The version and setting of solar radio intensity (F10.7) and geomagnetic activity $\left(A_{p}\right)$ were Ver. 81 (Feb 2017). The AO fluence calculated by the MSIS model was found to be close to that calculated by measuring the erosion depth (step heights) of the Vespel. Therefore, it was suggested that the AO fluence estimated by the MSIS model has some validity.

Based on the above results, the AO fluence during the exposure should be examined over a range of values. Considering the measured mass loss and erosion depth of the Vespel, the fluence was $1.3-2.1 \times 10^{21}$ atoms $/ \mathrm{cm}^{2}$, 
corresponding to a mass loss per area of the Vespel of $5.4-8.8 \times 10^{-3} \mathrm{~g} / \mathrm{cm}^{2}$.

\subsection{UV irradiance}

The UV irradiance on the samples during the exposure in the MDM2 was also calculated using the JAXA SEES [32]. The irradiance at $200-400 \mathrm{~nm}$ was $9.95 \times 10^{8} \mathrm{~J} / \mathrm{m}^{2}$ from May 26, 2015 to June 13, 2016, corresponding to 98 ESD (solar equivalent days, $1 \mathrm{ESD}=1.02 \times 10^{7} \mathrm{~J} / \mathrm{m}^{2}$ ). In this calculation, the settings of orbital elements and angles of the exposed surface were the same as those of the AO fluence calculation mentioned above.

\subsection{Changes in appearance and thermo-optical properties}

To identify the degree of degradation of the eleven thermal control materials by exposure in the MDM2, the changes in their appearance were observed, and those in thermooptical properties (UV-Vis-NIR reflectance spectra, $\alpha_{s}$, and $\left.\varepsilon_{N}\right)$ were measured. Figures 6 and 8 show the thermal control film samples used as MLIs and OSRs, before and after exposure. Figures 7 and 9 show the film samples' reflectance spectra before and after exposure and these difference spectra. Table 2 shows the thermo-optical property $\left(\alpha_{s}\right.$ and $\left.\varepsilon_{N}\right)$ changes and their ratios.

First, the appearance and thermo-optical property changes to the five film samples used as MLIs are described. The exposed surfaces of the $S Q$-coated polyimide film, the BSF30 film, and the Beta Cloth (Fig. 6a, b, e) were discolored.
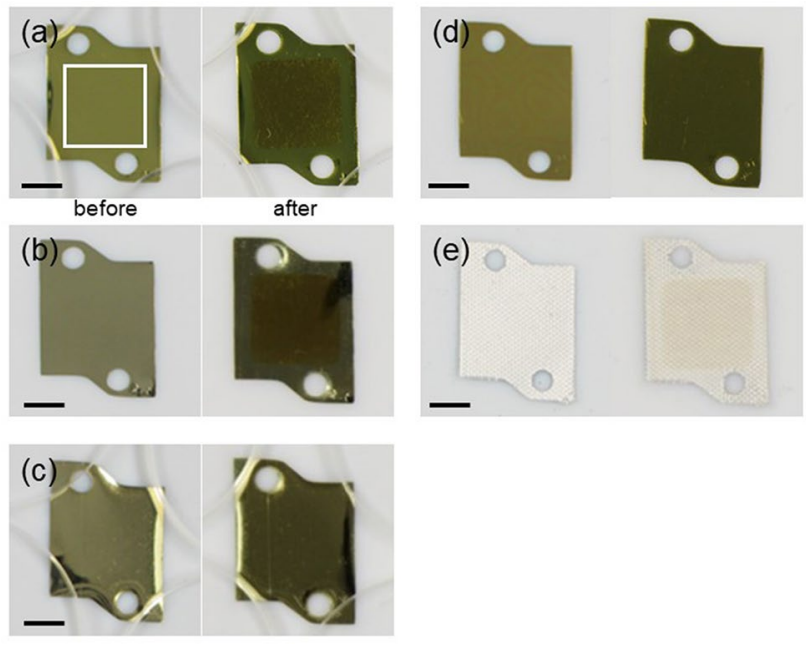

Fig. 6 Photographs of the film samples used as MLIs before (left) and after (right) exposure: a $S Q$-coated polyimide film, b BSF-30 film, c UV-shielded BSF-30 film, d ITO-coated polyimide film, and e Beta Cloth. A white square in (a) shows a $1 \mathrm{~cm} \times 1 \mathrm{~cm}$ exposed area. Scale bars indicate $5 \mathrm{~mm}$

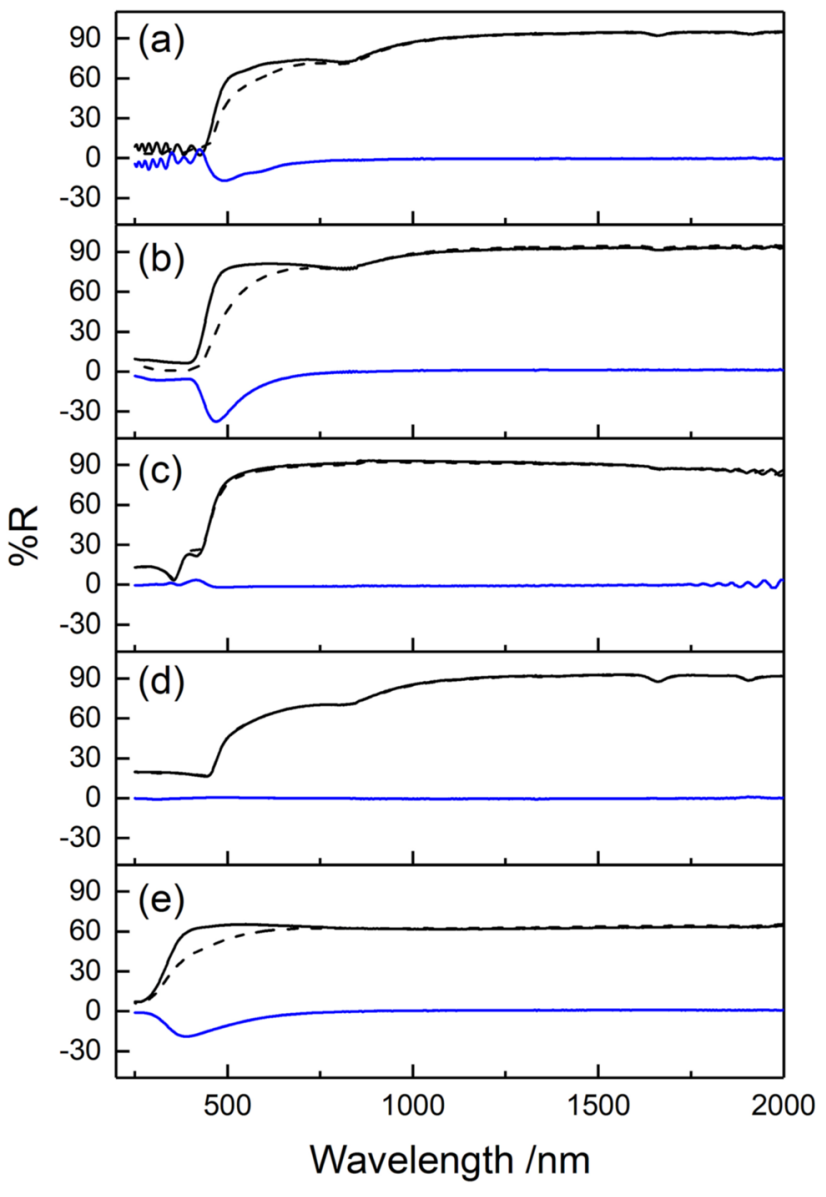

Fig. 7 UV-Vis-NIR reflectance spectra of the film samples used as MLIs before (solid black line) and after exposure (dashed black line): a $S Q$-coated polyimide film, b BSF-30 film, c UV-shielded BSF30 film, d ITO-coated polyimide film, and e Beta Cloth. Blue lines show the difference spectra obtained by subtracting a spectrum before exposure from that after exposure

Their reflectance slightly decreased due to the exposure in the wavelength of $400-750 \mathrm{~nm}$ for the $S Q$-coated polyimide film and the BSF-30 film, and the 300-650 nm for the Beta Cloth (Fig. 7a, b, e). Considering that their transmittance is negligible because of an $\mathrm{Al}$ layer on their back surface, such reflectance decreases indicate absorptance increases at the same wavelength. Their $\alpha_{s}$ values, which were calculated by substituting the reflectance (as a function of wavelength) for Eq. (1), increased by $10 \%$ for the $S Q$-coated polyimide film and the Beta Cloth and 30\% for the BSF-30 film (Table 2).

These discolorations and decreases in the reflectance at UV-Vis (300-750 $\mathrm{nm})$ regions, which affect the increases in $\alpha_{s}$, are likely due to UV from the Sun. It is known that polymers become yellow with UV exposure [33]. UV breaks chemical bonds such as $\mathrm{C}=\mathrm{C}$ and $\mathrm{C}=\mathrm{O}$ in polymers, forming radical species. The radical species lead to rearrangement of the chemical bonds, resulting in the yellowing of the polymer surfaces. Thus, UV reactions with polymers, such as the 
Table 2 Solar absorptances $\left(\alpha_{s}\right)$ and normal infrared emittances $\left(\varepsilon_{N}\right)$ before and after exposure, and their change ratios of the film samples

\begin{tabular}{|c|c|c|c|c|c|c|c|}
\hline \multirow{2}{*}{$\begin{array}{l}\text { Installed } \\
\text { position }\end{array}$} & \multirow[t]{2}{*}{ Material sample } & \multicolumn{3}{|l|}{$\alpha_{s}$} & \multicolumn{3}{|l|}{$\varepsilon_{N}$} \\
\hline & & Before & After & Change ratio & Before & After & Change ratio \\
\hline 2 & AO protective coating ( $S Q$-coating)/polyimide film (Upilex-R)/Al & 0.34 & 0.38 & 1.1 & 0.80 & 0.77 & 0.96 \\
\hline 3 & AO protective polyimide film (BSF-30)/Al & 0.27 & 0.34 & 1.3 & 0.82 & 0.82 & 1.0 \\
\hline 4 & UV-shielding coating/AO protective polyimide film (BSF-30)/Ag & 0.23 & 0.24 & 1.0 & 0.83 & 0.83 & 1.0 \\
\hline 10 & ITO coating/polyimide film (Upilex-R)/Al & 0.37 & 0.37 & 1.0 & 0.84 & 0.85 & 1.0 \\
\hline 12 & Beta Cloth/Al & 0.39 & 0.43 & 1.1 & 0.96 & 0.96 & 1.0 \\
\hline 9 & FEP (1 mil) film/Ag & 0.07 & 0.30 & 4.3 & 0.57 & 0.60 & 1.1 \\
\hline 11 & FEP (5 mil) film/Ag & 0.07 & 0.12 & 1.7 & 0.86 & 0.85 & 0.99 \\
\hline 13 & ITO coating/FEP ( 5 mil) film/Ag & 0.08 & 0.17 & 2.1 & 0.86 & 0.86 & 1.0 \\
\hline 14 & Flexible-OSR 1 & 0.18 & 0.19 & 1.1 & 0.88 & 0.89 & 1.0 \\
\hline 15 & Flexible-OSR 2 & 0.19 & 0.19 & 1.0 & 0.85 & 0.90 & 1.1 \\
\hline 16 & Flexible-OSR 3 & 0.18 & 0.19 & 1.1 & 0.86 & 0.87 & 1.0 \\
\hline
\end{tabular}

Fig. 8 Photographs of the exposed faces of the film samples used as OSRs before (left) and after (right) exposure: a FEP (1 mil)/Ag, b FEP (5 mil)/ Ag, c ITO-coated FEP (5 mil)/ $\mathrm{Ag}$, and $\mathbf{d}-\mathbf{f}$ flexible-OSR $1-3$. For the FEP/Ag films, the photographs of their back face are also shown. White ovals in (a) show $\mathrm{Ag} / \mathrm{Inconel}$ peeling. Scale bars indicate $5 \mathrm{~mm}$
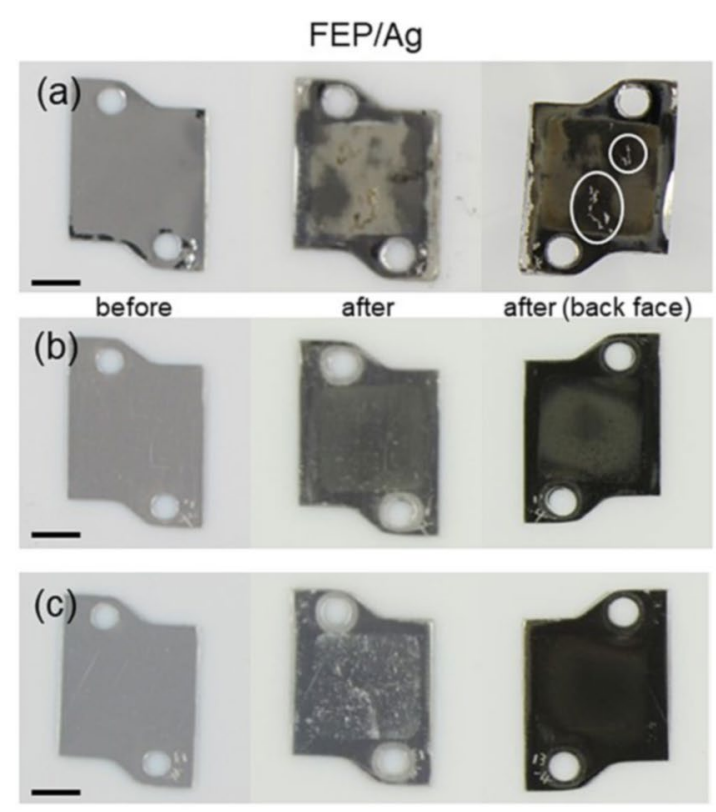

Flexible-OSR
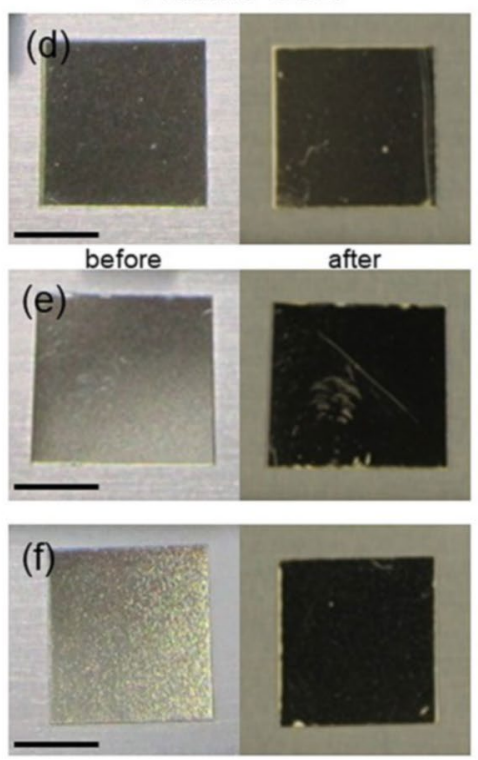

$S Q$-coating, the BSF-30 film, the FEP included in the Beta Cloth, and their polymeric additives probably caused such discolorations and decreased the reflectance. In fact, several studies have reported their discoloration and increase of $\alpha_{s}$ values due to ground-based UV irradiation for the $S Q$-coated polyimide film [20] and space exposure for the BSF-30 film and the Beta Cloth [25, 28]. In particular, the $\alpha_{s}$ increase of the Beta Cloth at a UV irradiance here was similar to that measured in the previous space exposures (MISSE experiments) [28].

On the other hand, no visual change was noticeable for the UV-shielded BSF-30 film or the ITO-coated polyimide (Upilex-R) film (Fig. 6c, d), and their reflectance (Fig. 7c, d), and the $\alpha_{s}$ value (Table 2) did not change either. These results show that the UV-shielding coating composed of
ITO and $\mathrm{CeO}_{2}$ provides enough $\mathrm{UV}$-shielding to prevent the BSF-30 base film from discoloring. The ITO coating and/ or Upilex-R film itself are strongly UV resistant. The high UV resistance of a Upilex-R film has also been reported in a study of UV irradiation [34]. Also, it was confirmed that the thermo-optical property of these materials was maintained under an AO fluence of $1.3-2.1 \times 10^{21}$ atoms $/ \mathrm{cm}^{2}$.

The $\varepsilon_{N}$ value of the $S Q$-coated polyimide film decreased slightly in this exposure; those of the other films did not change (Table 2). In general, $\varepsilon_{N}$ depends on the chemical structure of a material and its surface morphology. The reaction of the $S Q$-coating with AO and UV affected both its chemical structure and its surface morphology, as described below. Considering the characteristics of these reactions, the observed $\varepsilon_{N}$ decrease was mainly due to the change in 


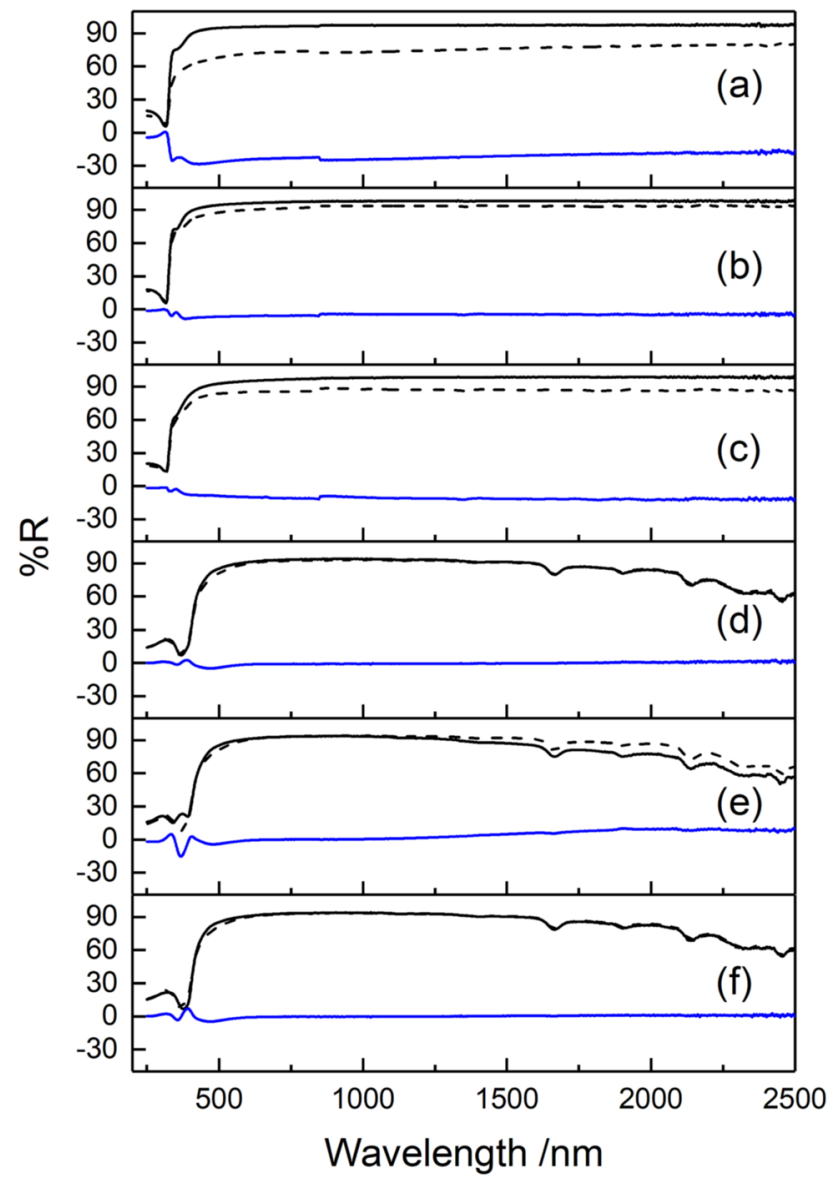

Fig. 9 UV-Vis-NIR reflectance spectra of the film samples used as OSRs before (solid black line) and after exposure (dashed black line): a FEP (1 mil)/Ag, b FEP (5 mil)/Ag, c ITO-coated FEP (5 mil)/Ag, and $\mathbf{d}-\mathbf{f}$ flexible-OSR $1-3$. Blue lines show the difference spectra obtained by subtracting a spectrum before exposure from that after exposure

the chemical structure of the coating surface by AO, such as forming a silica layer. The details of the surface reactions are discussed in Sect. 3.5.

Next, the appearance and thermo-optical property changes to the three silver-coated FEP (FEP/Ag) films used as OSRs are described. The exposed surfaces of the FEP (1 mil)/Ag and FEP (5 mil)/Ag films appeared smooth, although it is difficult to tell from the pictures (Fig. 8a, b) because of the high transparency of the FEP films. The surface of the ITO-coated FEP (5 mil)/Ag film was clouded (Fig. 8c). The ITO coating is prone to physical damage; therefore, its visual change in the sample is likely due to ITO defects. Their back surfaces, composed of a 150-nmthick Ag layer and a 30-nm-thick Inconel (Ni alloy) layer, were partially discolored to a light black due to the exposure (Fig. 8a-c). In particular, the change in the FEP (1 mil)/ Ag film was severe; part of its Ag/Inconel layer had peeled off (Fig. 8a). Their reflectance decreased at wavelengths

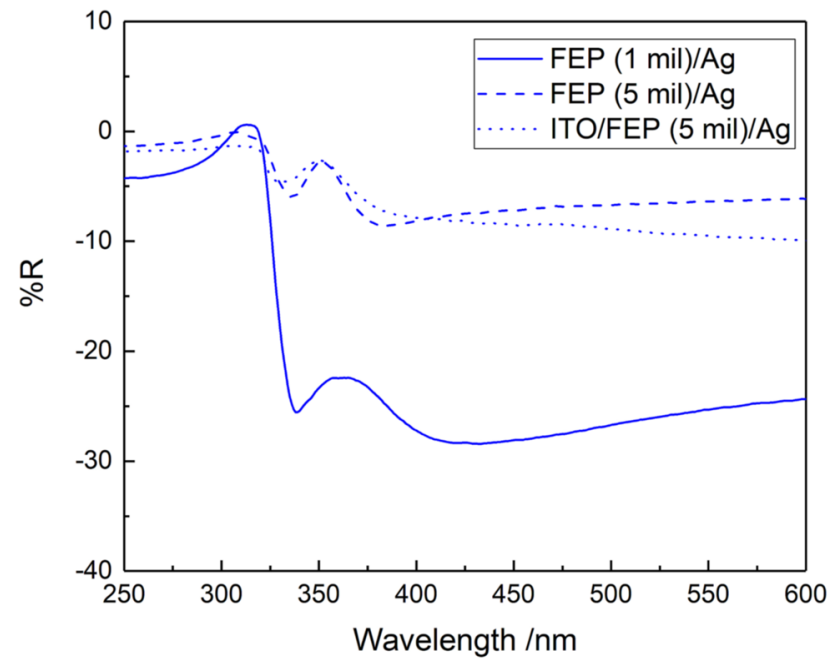

Fig. 10 Enlarged difference spectra of the FEP (1 mil)/Ag (solid), the FEP (5 mil)/Ag (dashed), and the ITO-coated FEP (5 mil)/Ag (dotted), obtained by subtracting a UV-Vis-NIR reflectance spectrum before exposure from that after exposure

above $320 \mathrm{~nm}$ (Fig. 9a-c), and the decrease was large in the FEP $(1 \mathrm{mil}) / \mathrm{Ag}$ film. Although their $\varepsilon_{N}$ values did not change significantly, the exposure increased their $\alpha_{s}$ values by $170-430 \%$ (Table 2). These results suggest that the Ag layers were oxidized by $\mathrm{AO}$, which arrived at their surfaces via multiple scattering. It is known that $\mathrm{AO}$ can oxidize $\mathrm{Ag}$ even at room temperature [35-37], forming nanoscale grains composed of $\mathrm{AgO}$ and $\mathrm{Ag}_{2} \mathrm{O}$ on its surface [36,37]. On the reflectance difference spectra of the FEP/Ag films, absorption peaks were observed at $430 \mathrm{~nm}$ for the FEP (1 mil)/Ag film and $380 \mathrm{~nm}$ for the FEP (5 mil)/Ag film (Fig. 10). These visible wavelengths are similar to those of the plasmon resonance absorption peaks of $\mathrm{Ag}_{2} \mathrm{O}$ nanoparticles [38]. Based on these, the discolorations, decrease in the reflectance, and significant increases of the $\alpha_{s}$ values of the FEP/Ag films seem to occur mainly due to oxidation of the Ag layers by AO. However, the details of the phenomenon have not been clarified yet. There remain two questions. First is why, the FEP (1 mil)/Ag film's damage was more severe than that of the other FEP/Ag films with the same-thickness Ag/Inconel layer as the FEP (1 mil)/Ag film. The second is why the Ag layer under the Inconel layer oxidized. In our future study, we will examine the detailed reactions of the $\mathrm{Ag} / \mathrm{Inconel}$ layers with $\mathrm{AO}$, based on their surface analysis results.

Next, the changes to the three flexible OSRs are described. No apparent changes in appearances or thermooptical properties ( $\alpha_{s}$ and $\varepsilon_{N}$ values) were found for the three types of flexible OSRs (Table 2). Their reflectance spectra did not change much except in the IR region for the flexibleOSR-2 (Fig. 9d, e). The reflectance of the flexible-OSR-2 slightly increased above $1200 \mathrm{~nm}$ increased slightly due to the exposure. Although it is not clear why this reflectance 
increase was observed only for the flexible-OSR-2, several scratches on its surface (Fig. 8e) might have affected the uncertainty in the reflectance. After all, it was confirmed that the thermo-optical property of the three flexible OSRs was maintained under the AO fluence of $1.3-2.1 \times 10^{21}$ atoms/ $\mathrm{cm}^{2}$ and a UV irradiance of $98 \mathrm{ESD}$.

\subsection{Changes in mass}

To identify the degree of degradation by exposure of the eight thermal control materials (except for the flexible OSRs attached to the sample holder by an adhesive), their mass changes were measured. Table 3 shows the mass losses and their ratios to the Vespel.

Beginning with the five film samples used as MLIs, the mass losses of the $S Q$-coated polyimide film, the two types of BSF-30 films, and the ITO-coated polyimide film to the Vespel were $1 \%$ or less; that of the Beta Cloth was 5-8\%. These results show their high resistance to AO erosion.

The mass loss of the $S Q$-coated polyimide film was $0.9-1 \%$ that of the Vespel; this means that its mass loss in the MDM2 was twice as large as that in ground-based AO irradiation [20]. Although it is not clear why the mass loss was larger in the LEO exposure, the $S Q$-coated polyimide film seems to be susceptible to environmental differences between space and ground-based irradiation. The mass loss of the BSF-30 film was $0.2-0.4 \%$ that of the Vespel; the mass loss ratio was almost the same as that obtained in a previous space exposure experiment onboard the ISS [25]. Therefore, the reproducibility of mass loss due to AO was confirmed for the BSF-30 film here. Besides, the reaction amount ratio of the $S Q$-coated polyimide film to the Vespel in the MDM2 was the same or slightly less than those of polyhedral oligomeric silsesquioxane (POSS)-containing polyimide materials to Kapton $\mathrm{H}$ in $\mathrm{AO}$ irradiation (1\% or more in erosion depth at $8.5 \times 10^{20}$ atoms $/ \mathrm{cm}^{2}$ [39]) or LEO exposure $\left(0.9-2 \%\right.$ at $8 \times 10^{21}$ atoms $/ \mathrm{cm}^{2}$ in MISSE- 1 , and $1-2 \%$ at $1.97 \times 10^{21}$ atoms $/ \mathrm{cm}^{2}$ in MISSE-6 in erosion depths
[40]). The reaction amount ratio of the BSF-30 film to the Vespel here was extremely lower than those of other siloxane-containing materials to Kapton $\mathrm{H}\left(4 \%\right.$ at $1 \times 10^{21}$ atoms/ $\mathrm{cm}^{2}$ [41], $10 \%$ or more at $2.8 \times 10^{20}$ atoms $/ \mathrm{cm}^{2}$ [42], and $6 \%$ or more at $3.9 \times 10^{20}$ atoms $/ \mathrm{cm}^{2}$ [43] in AO irradiation in mass losses). The reason why the erosion of the BSF-30 film was very small compared to those of the $S Q$-coated polyimide film and POSS- and siloxane-containing materials is discussed in Sect. 3.5, based on the results of XPS analyses and FE-SEM observations. For the UV-shielded BSF-30 film, a slight increase of the mass was observed. Since this material has four layers (ITO, $\mathrm{CeO}_{2}, \mathrm{BSF}-30 \mathrm{film}$, and $\mathrm{Ag}$ ) which might interact with $\mathrm{AO}$ and the mass gain was tiny $\left(0.01 \mathrm{mg} / \mathrm{cm}^{2}\right)$, it is difficult to identify the reactions that affected it. After all, the mass of the UV-shielded BSF-30 film did not decrease compared with the uncoated-BSF film; therefore, the UV-shielding coating was found to have both UV-shielding and AO resistance properties.

The mass loss of the ITO-coated polyimide film was $0.9-1 \%$ that of the Vespel. The mass loss ratio was almost the same as that obtained in past ground-based irradiation [44]. For the Beta Cloth, the mass loss was slightly higher than those of the other MLI films. Considering the AO erosion yield of Beta Cloth, such as $2.0 \times 10^{-25} \mathrm{~cm}^{3} /$ atom (provided by a space exposure experiment LDEF [29]), the mass loss here is reasonable.

Next, the mass losses of the three silver-coated FEP films used as OSRs are described. The mass losses of the FEP $(1 \mathrm{mil}) / \mathrm{Ag}$ and the FEP $(5 \mathrm{mil}) / \mathrm{Ag}$ were 0.56 and $0.52 \mathrm{mg} /$ $\mathrm{cm}^{2}$, and $6-10 \%$ that of the Vespel. Since these values include the contributions of oxidation of the Ag layer, peeling of the $\mathrm{Ag} / \mathrm{Inconel}$ layer, and erosion of the FEP due to $\mathrm{AO}$ attacks, it is difficult to discuss $\mathrm{AO}$ erosion yields of the FEP film based on them. Thus, to quantify the erosion extent of the FEP film individually, the erosion depth of the silvercoated FEP films was also measured by FE-SEM observation. Figure 11 shows cross-sectional FE-SEM images of the FEP (1 mil)/Ag (Fig. 11a, b) and the FEP (5 mil)/Ag

Table 3 Mass losses and mass change ratios of the film samples during exposure

\begin{tabular}{llcc}
\hline $\begin{array}{l}\text { Installed posi- } \\
\text { tion }\end{array}$ & Material sample & $\begin{array}{l}\text { Mass loss per area/ } \\
\mathrm{mg} / \mathrm{cm}^{2}\end{array}$ & $\begin{array}{l}\text { Mass loss ratio to Vespel }{ }^{\mathrm{a})} \\
2\end{array}$ \\
\hline 3 & AO protective coating (SQ-coating)/polyimide film (Upilex-R)/Al & 0.08 & 0.009 to 0.01 \\
4 & AO protective polyimide film (BSF-30)/Al & 0.02 & 0.002 to 0.004 \\
10 & UV-shielding coating/AO protective polyimide film (BSF-30)/Ag & -0.01 & -0.002 to -0.001 \\
12 & ITO coating/polyimide film (Upilex-R)/Al & 0.08 & 0.009 to 0.01 \\
9 & Beta Cloth/Al & 0.45 & 0.051 to 0.083 \\
11 & FEP (1 mil) film/Ag & 0.56 & 0.064 to 0.10 \\
13 & FEP (5 mil) film/Ag & 0.52 & 0.059 to 0.096 \\
\hline
\end{tabular}

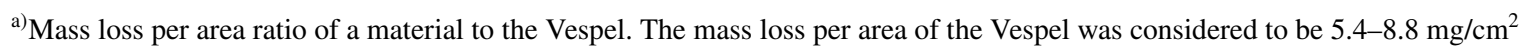


Fig. 11 Cross-sectional FESEM images of the FEP (1 mil)/ $\operatorname{Ag}(\mathbf{a}, \mathbf{b})$ and the FEP (5 mil)/ $\mathrm{Ag}(\mathbf{c}, \mathbf{d})$ films. a, c The images observed before exposure; $\mathbf{b}, \mathbf{d}$ show those observed after exposure. The acceleration voltage was $0.8 \mathrm{kV}$
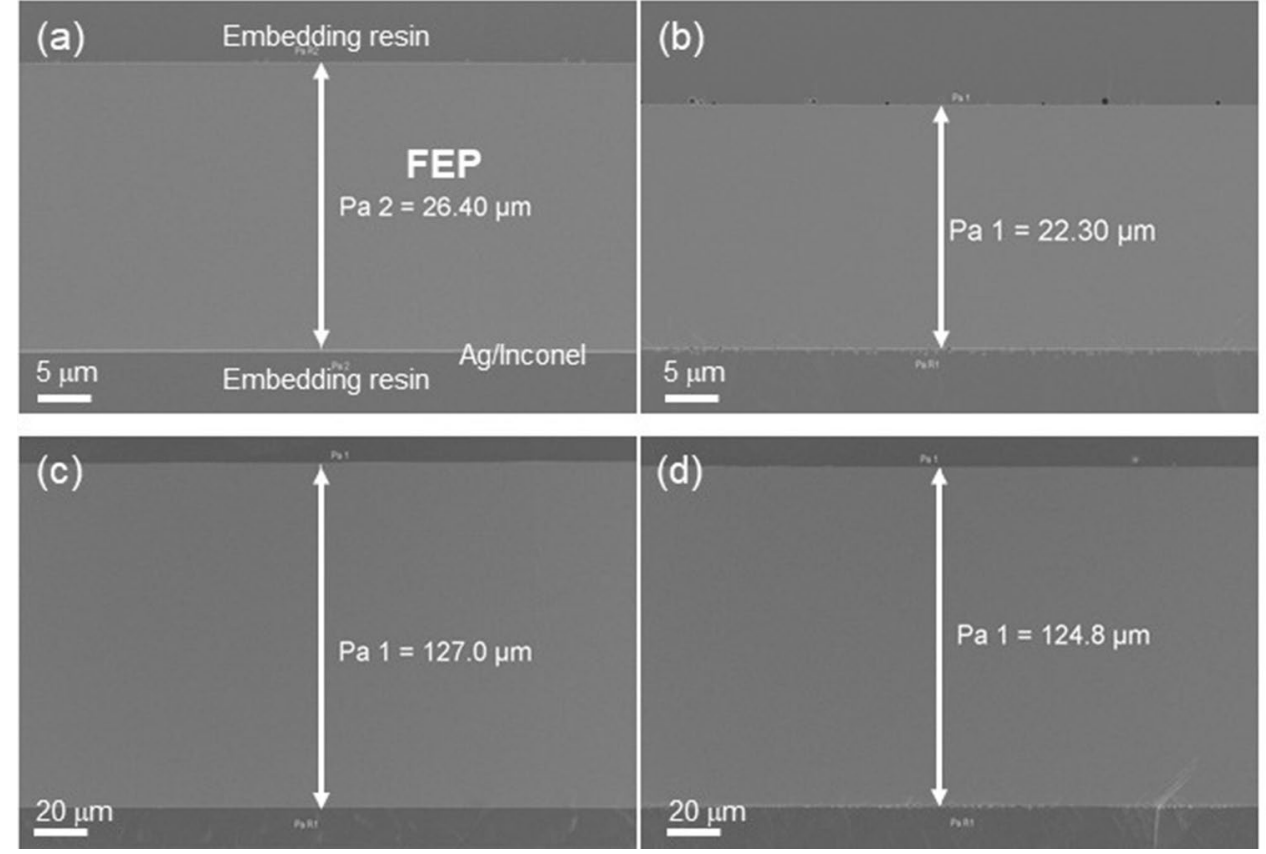

(Fig. 11c, d), before and after exposure. As a result, the erosion depths of the FEP ( $1 \mathrm{mil})$ and the FEP (5 mil) films were 4 and $2 \mathrm{~mm}$. These correspond to the mass losses of 0.86 and $0.43 \mathrm{mg} / \mathrm{cm}^{2}, 10-16 \%$, and $5-8 \%$ of that of the Vespel (assuming the FEP film's density to be $2.15 \mathrm{~g} / \mathrm{cm}^{3}$ ). Based on the measured erosion depths and Eq. (4), the AO erosion yields of the FEP ( $1 \mathrm{mil}$ ) and the FEP (5 mil) films were calculated, $1.9-3.1 \times 10^{-25}$ and $0.95-1.5 \times 10^{-25} \mathrm{~cm}^{3} /$ atom, respectively. In a past study based on flight exposure experiments, it was found that solar exposure affects an erosion yield of FEP films, and the following empirical equation holds:

$y=3.24 \times 10^{-29} x^{1.07}$

where $y$ is an erosion yield $\left(E_{y}\right)$ of an FEP film, and $x$ is equivalent solar hours (ESH) [6]. Figure 12 shows the erosion yields of the FEP (1 mil) and the FEP (5 mil) films obtained from the erosion depths, and those estimated by the empirical equation. Although the obtained erosion yields were roughly the same as the estimated values, that of the FEP (1 mil) film was slightly higher. Assuming that the AO fluences on both the FEP films were likely to be the same, the significant $\alpha_{s}$ increase in the FEP (1 mil)/Ag film (Table 2) might increase solar heating, and cause the erosion yield increase. Further studies are needed to clarify the relation between erosion yield and the thermo-optical property of the silver-coated FEP films. Besides, the mass loss of the ITO-coated FEP (5 mil)/Ag film was less than $10 \%$ those of the uncoated ones; its sufficient $\mathrm{AO}$ resistance was confirmed.

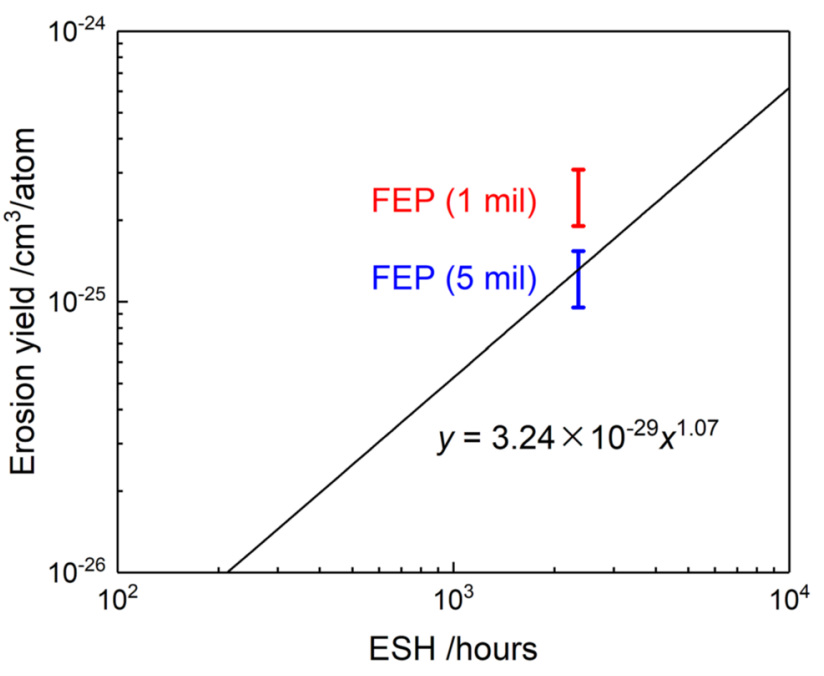

Fig. 12 Erosion yields of the 1 mil FEP and the 5 mil FEP films (calculated from their erosion depth) as a function of equivalent solar hours (ESH). The solid line shows an empirical equation that expresses the correlation between an erosion yield of an FEP film and ESH [6]

\subsection{Reactions of resistant materials with AO}

To understand the detailed reactions of AO with the $S Q$ coated polyimide film, the BSF-30 film, and the UV-shielded BSF-30 film, the films' surfaces were analyzed by XPS, and observed by FE-SEM before and after exposure.

The XPS analysis results of their top-surface elemental composition are summarized in Table 4. It was found that $\mathrm{C}$ concentration decreased and that $\mathrm{O}$ and $\mathrm{Si}$ 
Table 4 Elemental compositions of top surface of the $S Q$-coated polyimide film, the BSF-30 film, and the UV-shielded BSF-30 film before and after exposure, analyzed by XPS

\begin{tabular}{lllllllllll}
\hline $\begin{array}{l}\text { Installed } \\
\text { position }\end{array}$ & Material sample & Exposure & $\mathrm{C}$ & $\mathrm{N}$ & $\mathrm{O}$ & $\mathrm{Si}$ & $\mathrm{In}$ & $\mathrm{Sn}$ & $\mathrm{Ce}$ & $\mathrm{F}$ \\
\hline 2 & \multirow{2}{*}{$S Q$-coated polyimide film } & Before & 56 & $-{ }^{\text {a) }}$ & 30 & 14 & - & - & - & - \\
& & After & 6.8 & - & 58 & 35 & - & - & - & - \\
3 & \multirow{3}{*}{ BSF-30 film } & Before & 65 & 2.9 & 19 & 11 & - & - & - & - \\
& & After & 7.2 & 0.6 & 59 & 33 & - & - & - & - \\
4 & \multirow{3}{*}{ UV-shielded BSF-30 film } & Before & 17 & 0.4 & 46 & 0.8 & 33 & 3.3 & 0.3 & 0.6 \\
& & After & 14 & 0.0 & 47 & 0.0 & 32 & 3 & 0.4 & 1.7 \\
\hline
\end{tabular}

C, N, O, S, Si, In, Sn, Ce, and F show the elemental concentrations in the unit of atom\% calculated from peaks of the XPS spectra of C(1s), N(1s), O(1s), S(2p), Si(2p), In(3d), Sn(3d), Ce(3d), and F(1s), respectively

${ }^{\text {a) }}$ Dashes (-) indicate unmeasured values concentrations increased due to the exposure to the AO fluence of $1.3-2.1 \times 10^{21}$ atoms $/ \mathrm{cm}^{2}$ on the $S Q$-coated polyimide film and the BSF-30 film surfaces. The $\mathrm{C}$ concentrations decreased from 56 and 65 to $7 \%$, and the $\mathrm{Si}$ : O ratios resulted in approximately $1: 1.7$ and $1: 1.8$ on these samples.

To clarify chemical bonding state changes that affected such composition changes, high-resolution XPS spectra of $\mathrm{Si}(2 \mathrm{p}), \mathrm{C}(1 \mathrm{~s})$, and $\mathrm{O}(1 \mathrm{~s})$, the binding energies of which are 96-110 eV, 280-295 eV, and 525-545 eV, were focused, as shown in Fig. 13. In these spectra, the shift due to sample charging was corrected by assuming that the lowest $\mathrm{C}(1 \mathrm{~s})$ component's binding energy is $285.0 \mathrm{eV}$. For the $S Q$-coating (Fig. 13a), the $\mathrm{Si}(2 \mathrm{p})$ peak detected on the unexposed coating (102.4 eV, assigned to silsesquioxane frameworks such as $\mathrm{RSiO}_{3 / 2}$ ) was shifted to the higher binding energy of
$104.4 \mathrm{eV}$ by the exposure. The $\mathrm{Si}(2 \mathrm{p})$ peak of approximately $104 \mathrm{eV}$ can be assigned to silica $\left(\mathrm{SiO}_{2}\right)$ [45]; therefore, the result shows that the silsesquioxane frameworks reacted with $\mathrm{AO}$, resulting in the formation of a silica layer. In the $\mathrm{C}(1 \mathrm{~s})$ spectra, the hydrocarbon peak of $285.0 \mathrm{eV}$ became slightly broad at the high binding-energy side; the $\mathrm{C}=\mathrm{O}$ peak of $289.2 \mathrm{eV}$ became relatively weak by the exposure [45]. This result suggests that reactions of the organic components (the R units shown in Fig. 2a) in the coating with AO caused various carbon oxides on the surface and erosion. In addition, the $\mathrm{O}(1 \mathrm{~s})$ peak was shifted from 532.4 to $535.3 \mathrm{eV}$ by the exposure. The $\mathrm{O}(1 \mathrm{~s})$ peak of the exposed sample surface can be assigned mainly to the $\mathrm{O}$-atoms combined with $\mathrm{Si}$ atoms, considering its elemental composition (Table 4). The binding energy of an $\mathrm{O}(1 \mathrm{~s})$ peak of silica $\left(\mathrm{SiO}_{2}\right)$ is known to
Fig. 13 High-resolution XPS spectra of $\mathrm{Si}(2 \mathrm{p}), \mathrm{C}(1 \mathrm{~s})$, and $\mathrm{O}(1 \mathrm{~s})$ for top surface of $\mathbf{a}$ $S Q$-coated polyimide film and b BSF-30 film before (dashed lines) and after (solid lines) exposure [binding energies: $96-110 \mathrm{eV}$ for $\mathrm{Si}(2 \mathrm{p})$, 280-295 eV for C(1s), and $525-545 \mathrm{eV}$ for $\mathrm{O}(1 \mathrm{~s})]$

\section{(a) $S Q$ coating}
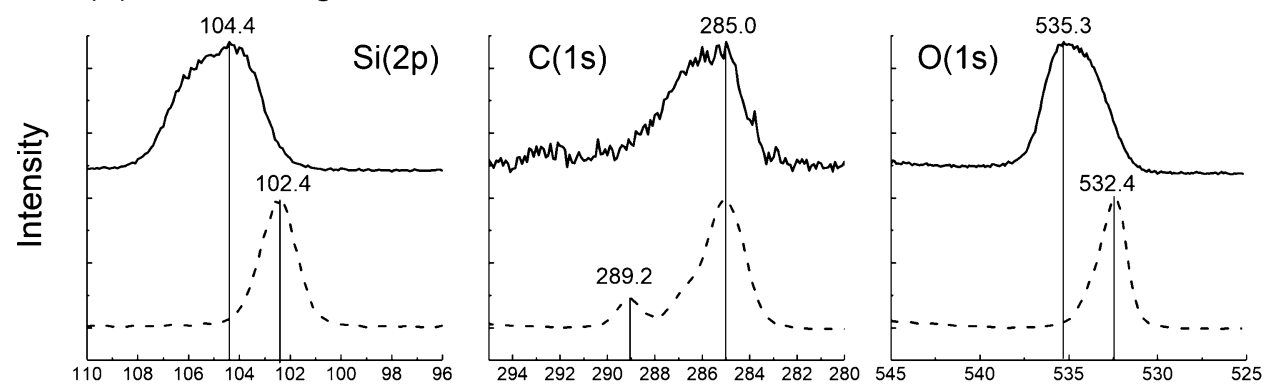

Binding energy /eV

(b) BSF-30 film

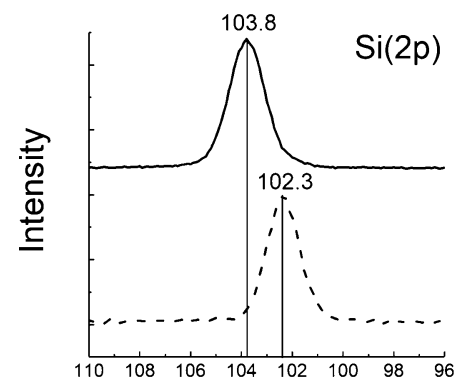

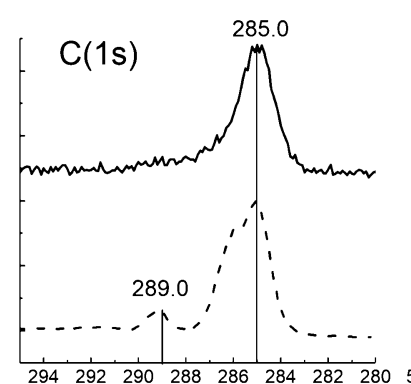

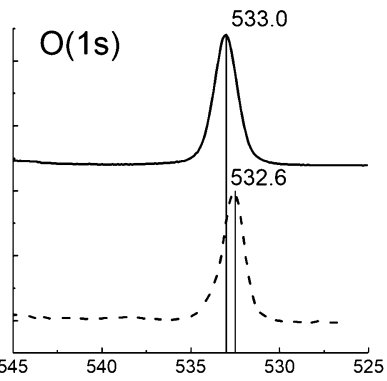

Binding energy /eV 
be $533 \mathrm{eV}$ [45]; therefore, the peak shift also indicates that $\mathrm{Si}$-atoms contained in the coating were oxidized to silica by AO.

Chemical bonding state changes on the BSF-30 film with AO were roughly similar to those of the $S Q$-coating (Fig. 13b). The $\mathrm{Si}(2 \mathrm{p})$ peak detected on the unexposed film $(102.3 \mathrm{eV}$, assigned to methylsiloxane structures such as $\left.\mathrm{Si}\left(\mathrm{CH}_{3}\right)_{2}\left(\mathrm{CH}_{2}\right) \mathrm{O}_{1 / 2}\right)$ was shifted to the higher binding energy of $103.8 \mathrm{eV}$ by the exposure. The $\mathrm{O}(1 \mathrm{~s})$ peak was also shifted from 542.6 to $533.0 \mathrm{eV}$. These results show that $\mathrm{Si}$-atoms contained in the BSF-30 film were oxidized to silica by AO. In the $\mathrm{C}(1 \mathrm{~s})$ spectra, the $\mathrm{C}=\mathrm{O}$ peak of $289.0 \mathrm{eV}$ became relatively weak or disappeared by the exposure. Reactions of the film's organic components with AO seem to change the oxidation state of the carbon on the surface with eroding.

Based on the results above, the surface reactions of the $S Q$-coating and the BSF- 30 with AO can be considered as follows. AO attacks their surface; organic components are oxidized and desorbed as volatile species from their surfaces. Then, the $\mathrm{Si}$-atoms in these materials react with $\mathrm{AO}$ and accumulate in a silica structure. The formed silica layer acts as a protective (passivating) layer that prevents the film from further erosion. Similar chemical bonding state changes in Si and O-atoms were detected on POSS- [39, 46-48] and siloxane-containing materials' surfaces after AO irradiation $[43,49,50]$ by XPS. Thus, the surface reactions of the $S Q$-coating and the BSF-30 film with AO are like those of other $\mathrm{Si}$-containing materials to some extent.

To investigate the reaction amounts with AO in detail, the elemental composition's depth distributions were also analyzed by XPS with Ar-ion etching. Figure 14 shows the silica-equivalent depth profiles of their surfaces. The thickness of the silica layer formed on the $S Q$-coating was four times as large as that formed on the BSF-30 film. The thickness of the silica layer formed on the $S Q$-coating was $80 \mathrm{~nm}$, assuming that the silica layer was where the $\mathrm{Si}$ and $\mathrm{O}$ compositions were constant in the shallow region (Fig. 14a). Under the silica layer, an intermediate layer between silica and the $S Q$-coating was also formed with a thickness of at least $170 \mathrm{~nm}$, where $\mathrm{Si}$ and $\mathrm{O}$ compositions changed according to etching depth. On the other hand, the thicknesses of the silica and the intermediate layer formed on the BSF-30 were both $20 \mathrm{~nm}$ (Fig. 14b). These results mean that the numbers of reacted $\mathrm{Si}$-atoms and desorbed $\mathrm{C}$-atoms on the $S Q$-coating surface were larger than those on the BSF-30 film surface under the same AO fluence. Such difference in the surface reaction amounts between the $S Q$-coating and the BSF-30 films seems to affect their mass loss difference (Table 3).

To understand the molecular design of protective materials resistant to $\mathrm{AO}$, the difference in the surface reaction amounts between the $S Q$-coating and the BSF-30 film should

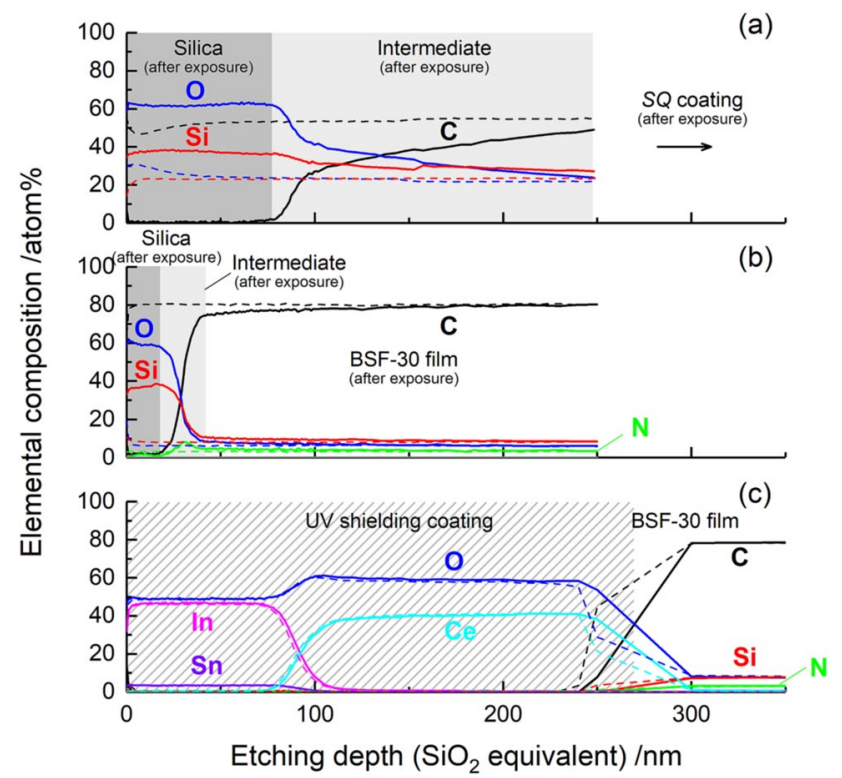

Fig. 14 Silica $\left(\mathrm{SiO}_{2}\right)$-equivalent depth profiles of the elemental composition of a $S Q$-coated polyimide film, b BSF-30 film, and c UVshielded BSF-30 film before (dashed lines) and after (solid lines) exposure, obtained by XPS with an Ar-ion etching. C, N, O, S, Si, In, $\mathrm{Sn}$, and $\mathrm{Ce}$ show the elemental compositions calculated by the highresolution XPS spectra of $\mathrm{C}(1 \mathrm{~s}), \mathrm{N}(1 \mathrm{~s}), \mathrm{O}(1 \mathrm{~s}), \mathrm{S}(2 \mathrm{p}), \mathrm{Si}(2 \mathrm{p}), \operatorname{In}(3 \mathrm{~d})$, $\operatorname{Sn}(3 d)$, and $\mathrm{Ce}(3 \mathrm{~d})$

be focused on. Despite their similar Si concentration of the unexposed samples (Table 4), the reaction amount with AO of the $S Q$-coating was significantly greater than that of the BSF-30 film (Table 3; Fig. 14). Several studies have reported that the AO erosion yield of POSS-containing polyimide materials decreased with increasing POSS (or Si) concentration [39, 40, 51]. The difference in the reaction amounts between the $S Q$-coating and the BSF-30 film contradicts such reports on POSS-containing materials. Although the cause of the difference has not been identified yet, it is likely due to the difference in the following two factors. First is the penetration depth of AO of their surface. As shown in Fig. 14a and b, the intermediate layer's thickness formed on the $S Q$-coating was eight times larger than that formed on the BSF-30 film. This fact suggests that the average penetration depth of AO into the $S Q$-coating was greater than that into the BSF-30 film. Their chemical structural difference (Fig. 2) can affect the polymer chains' packing; therefore, the $S Q$-coating density may be lower than that in the BSF30 film. Consequently, AO might be prone to penetrate, especially in the $S Q$-coating. The second is the denseness of the formed silica layer. As shown in Fig. 13, the $\operatorname{Si}(2 \mathrm{p})$ and $\mathrm{O}(1 \mathrm{~s})$ peaks of the high-resolution XPS spectra of the exposed $S Q$-coated polyimide film were slightly broader than those of the exposed BSF-30 film. This suggests that the silica layer formed on the $S Q$-coating was a mixture of silicon oxides in various oxidation states. The heterogeneity 
of the formed silica layer is probably due to the silsesquioxane derivatives with various chemical structures composing the $S Q$-coating itself, as shown in Fig. 2a. Such a formed heterogeneous silica layer seems to be difficult to accumulate densely; its protective ability against AO may be a little lower than that of a silica crystal with high density.

Also, to investigate the AO effects on surface morphology, the $S Q$-coated polyimide film surfaces and the BSF-30 film were observed by FE-SEM (Fig. 15a-d). It was found that the exposed surfaces of the $S Q$-coated polyimide film and the BSF-30 film were as smooth as the unexposed surfaces in nanoscale. However, microscale physical cracks were formed on the $S Q$-coated polyimide film surface during the exposure, as well (Fig. 15b). Strong internal stresses could occur in the in-plane direction near the surface, depending on the silica layer formation. The detailed mechanism related to the crack formation will be clarified in our future work using an AO-irradiation source. Since there is a possibility that the erosion from the crack positions increased the reaction amounts with AO (mass loss and chemical composition changes due to $\mathrm{AO}$ ), we will also investigate the crack formation effects on the $\mathrm{AO}$ protective ability of the coating.

As mentioned above, the mass loss ratio of the BSF-30 film to the Vespel was apparently lower than those of POSS$[39,40]$, other siloxane-containing materials [41-43], and
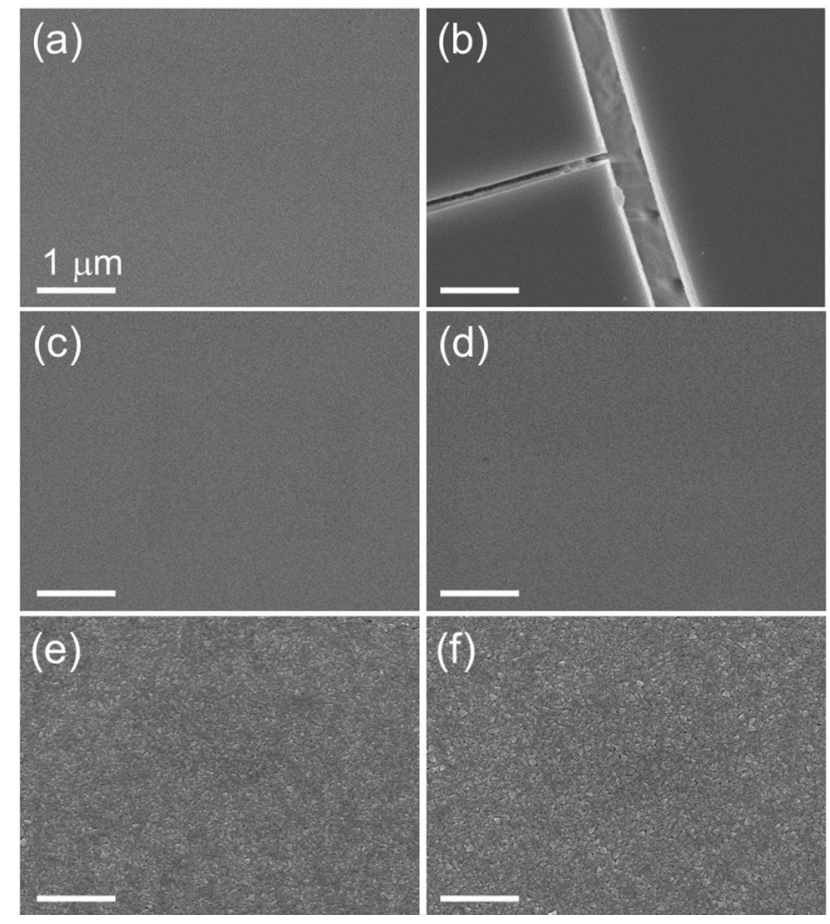

Fig. 15 FE-SEM images of the surfaces of $\mathbf{a}, \mathbf{b} S Q$-coated polyimide film, c, d BSF-30 film, and e, f UV-shielded BSF-30 film before (a, c, e) and after $(\mathbf{b}, \mathbf{d}, \mathbf{f})$ exposure. The acceleration voltage was $5 \mathrm{kV}$. The tilt angle was $0^{\circ}$. Scale bars show $1 \mu \mathrm{m}$ the $S Q$-coated polyimide film. Perhaps, the high AO resistance of the BSF-30 film is caused not only by its low AO penetrance but also by its high efficiency of silica formation. The POSS- and other siloxane-containing material surfaces became rough due to $\mathrm{AO}$ irradiation at the order of $10^{19}-10^{20}$ atoms $/ \mathrm{cm}^{2}$ [39, 40, 42, 43]. In contrast, the BSF-30 film surface exposed to AO at $1.3-2.1 \times 10^{21}$ atoms/ $\mathrm{cm}^{2}$ in the MDM2 was as smooth as the unexposed surface (Fig. 15c, d). This result suggests that a steady-state silica layer was formed on its surface before the polyimide backbone became rough due to $\mathrm{AO}$ attack. Its polymer conformation (higher order structure) may allow siloxane structures to preferentially react with $\mathrm{AO}$, compared to polyimide structures. After all, the high AO resistance of the BSF-30 film could be demonstrated from the morphological change, as well.

Besides, the surface elemental composition of the UVshielded BSF-30 film did not change much during the exposure (Table 4; Fig. 14c). Regardless of the exposure, In, $\mathrm{Sn}, \mathrm{Ce}$, and $\mathrm{O}$ assigned to the UV-shielded coating were detected on the surface. In addition, no noticeable change was observed on its surface by FE-SEM (Fig. 15e, f). These results also show that this UV-shielding coating has a high AO protective ability.

\section{Conclusion}

In the MDM2 mission, 11 types of thermal control films for future VLEO satellites were exposed to the LEO on the ISS for 1 year to understand their surface reactions and degradation at a given $\mathrm{AO}$ fluence and UV irradiance. The AO fluence during the exposure was calculated to be $1.3-2.1 \times 10^{21}$ atoms $/ \mathrm{cm}^{2}$ from measurements of the mass loss and erosion depth of the Vespel; the UV irradiance was calculated as $98 \mathrm{ESD}$ (equivalent solar days) using the JAXA SEES [32]. Five MLI films (a silsesquioxanecontaining coated [SQ-coated] polyimide film, two types of polysiloxane-block polyimide [BSF-30] film, an ITO-coated polyimide film, and a Beta Cloth) and flexible OSRs were found to have a high resistance to erosion caused by AO exposure, according to measurements of their mass loss and thermo-optical property changes. In particular, the UVshielded BSF-30 film, the ITO-coated polyimide film, and the flexible OSRs also quantitatively demonstrated their high UV-discoloration resistance. For three types of FEP/ $\mathrm{Ag}$ films, discoloration and peeling of their Ag/Inconel layer were observed, probably due to oxidation of the Ag layer by AO. Details of these oxidation phenomena remain to be determined by our future work.

Also, it was found that reactions with $\mathrm{AO}$ on the $S Q$ coating surface and the BSF-30 film formed a protective (passivating) silica layer, according to XPS analyses. Even 
though the Si concentration is the same or more than that of the BSF-30 film, the reaction amount of the $S Q$-coating was larger than that of the BSF-30 film at the same AO fluence. The difference in AO penetration depth on the surface and denseness of the formed silica layer may affect their reaction amounts with AO. It was also found by FE-SEM observation that multiple cracks were formed due to the exposure of the $S Q$-coated polyimide film surface. The detailed mechanism of this crack formation will be investigated by an AO-irradiation source in our work. Moreover, the effective ability of the UV-shielding coating, composed of ITO and $\mathrm{CeO}_{2}$ coated onto one of the BSF-30 films, was demonstrated by $\mathrm{UV}-\mathrm{Vis}$ spectrometry. Its sufficient AO protective ability was also confirmed by mass measurements, XPS analyses, and FE-SEM observations.

To clarify VLEO environmental effects on spacecraft materials, we would like to study high-flux AO and molecular nitrogen effects on the materials exposed in the MDM and MDM2 missions. The data on mass losses and thermooptical property changes (reflectance spectra) obtained in the MDM2 will be compared with the optical images (pixel values on the position of each sample) obtained in the MDM; then, it will be investigated whether reaction (degradation) amount at an AO fluence is the same between in-LEO and in-VLEO environments. Both missions have contributed to establishing design standards for VLEO satellites and the molecular design of more resistant materials.

Acknowledgements We thank all members involved in the ExHAM and MDM2 projects. We thank people from Toa-Gosei Co., Ltd. for their supply of the $S Q$-coated polyimide film. We thank people in NIPPON STEEL Chemical \& Material Co., Ltd. for their supply of the BSF-30 films. We thank people from Advanced Engineering Services Co., Ltd. for their support on the ground-based material analysis. A part of this work was conducted at the AIST Nano-Processing Facility supported by "Nanotechnology Platform Program" of the Ministry of Education, Culture, Sports, Science and Technology (MEXT), Japan. Grant Number JPMXP09F-20-AT-0089.

Funding JAXA's internal budget.

Data availability All data generated or analyzed during this study are included in this article.

Code availability N/A.

\section{Declarations}

Conflict of interest The authors have no conflict of interest directly relevant to the content of this article.

Open Access This article is licensed under a Creative Commons Attribution 4.0 International License, which permits use, sharing, adaptation, distribution and reproduction in any medium or format, as long as you give appropriate credit to the original author(s) and the source, provide a link to the Creative Commons licence, and indicate if changes were made. The images or other third party material in this article are included in the article's Creative Commons licence, unless indicated otherwise in a credit line to the material. If material is not included in the article's Creative Commons licence and your intended use is not permitted by statutory regulation or exceeds the permitted use, you will need to obtain permission directly from the copyright holder. To view a copy of this licence, visit http://creativecommons.org/licenses/by/4.0/.

\section{References}

1. Kawasaki, H., Konoue, K., Hoshino, H., Kaneko, Y., Sasaki, M.: Interim report of super low altitude satellite operation. In: Proc. of 2018 IEEE international geoscience and remote sensing symposium, pp. 4066-4069. (2018). https://doi.org/10.1109/IGARSS. 2018.8517529

2. Hoshino, H., Kaneko, Y., Sasaki, M.: SLATS and future prospectnew viewpoints for earth observation. In: Proc. of 31st international symposium on space technology and science (2017)

3. Minton, T.K., Garton, D.J.: Dynamics of atomic-oxygen-induced polymer degradation in low earth orbit. In: Dressler, R.A. (ed.) Chemical dynamics in extreme environments, pp. 420-489. World Scientific, Singapore (2001)

4. Banks, B.A., de Groh, K.K., Miller, S.K.: Low Earth Orbital Atomic Oxygen Interactions with Spacecraft Materials. NASA Technical Memorandum 2004-213400 (2004)

5. Picone, J.M., Hedin, A.E., Drob, D.P., Aikin, A.C.: NRLMSISE-00 empirical model of the atmosphere: Statistical comparisons and scientific issues. J. Geophys. Res. 107, 1468 (2002). https://doi.org/10.1029/2002ja009430

6. de Groh, K.K., Banks, B.A.: Atomic oxygen erosion data from the MISSE 2-8 missions. NASA Technical Memorandum 2019219982 (2019)

7. Shimamura, H., Nakamura, T.: Mechanical properties degradation of polyimide films irradiated by atomic oxygen. Polym. Degrad. Stab. 94, 1389-1396 (2009). https://doi.org/10.1016/j.polymdegra dstab.2009.05.013

8. Shimamura, H., Nakamura, T.: Investigation of degradation mechanisms in mechanical properties of polyimide films exposed to a low earth orbit environment. Polym. Degrad. Stab. 95, 21-33 (2010). https://doi.org/10.1016/j.polymdegradstab.2009.10.017

9. Zhang, J., Garton, D.J., Minton, T.K.: Reactive and inelastic scattering dynamics of hyperthermal oxygen atoms on a saturated hydrocarbon surface. J. Chem. Phys. 117, 6239-6251 (2002). https://doi.org/10.1063/1.1460858

10. Garton, D.J., Minton, T.K., Alagia, M., Balucani, N., Casavecchia, P., Volpi, G.: Atomic oxygen interactions with saturated hydrocarbon surfaces. In: A bound collection of papers: AIAA defense and space programs conference and exhibit - critical defense and space programs for the future. (1997). https://doi.org/10.2514/6. 1997-3947

11. Minton, T.K., Zhang, J., Garton, D.J., Seale, J.M.: Collisionassisted erosion of hydrocarbon polymers in atomic-oxygen environments. High Perform. Polym. 12, 27-42 (2000). https://doi.org/ 10.1088/0954-0083/12/1/303

12. Kimoto, Y., Tsuchiya, Y., Miyazaki, E., Goto, A., Yukumatsu, K., Imamura, S., Miura, T., Sasaki, M.: Analysis of first data from atomic oxygen monitor system onboard SLATS. In: Proc. of 14th international symposium on materials in the space environment and 12th international conference on protection of materials from space environment (2018)

13. Kimoto, Y., Yukumatsu, K., Goto, A., Miyazaki, E., Tsuchiya, Y.: MDM: a flight mission to observe materials degradation in-situ on satellite in super low Earth orbit. Acta Astronaut. 179, 695-701 (2021). https://doi.org/10.1016/j.actaastro.2020.11.048 
14. Goto, A., Kimoto, Y.: Material Degradation Monitor 2 (MDM2) mission: ground analysis results. In: Proc. of 14th international symposium on materials in the space environment and 12th international conference on protection of materials from space environment (2018)

15. Umeda, K., Goto, A., Kimoto, Y.: The surface analysis results of polysiloxane-block-polyimide (BSF-30) exposed to space environment. In: Proc. of 33rd international symposium on space technology and science (2019)

16. Watanabe, H., Sugi, N., Akagi, H.: The experiment plan using ExHAM on Japan experiment module, Kibo. In: Proc. of 60th the space sciences and technology conference (2016)

17. Yi, G.T., de Groh, K.K., Banks, B.A., Haloua, A., Imka, E.C., Mitchell, G.G.: Overview of the MISSE 7 polymers and zenith polymers experiment after 1.5 years of space exposure. In: NASA technical memorandum 2013-217848 (2013)

18. Kimoto, Y., Yano, K., Ishizawa, J., Miyazaki, E., Yamagata, I.: Passive space-environment-effect measurement on the international space station. J. Spacecr. Rockets 46, 22-27 (2009). https://doi.org/10.2514/1.31851

19. Kimoto, Y., Ishizawa, J., Shimamura, H.: Passive space environment effect measurement on JEM/MPAC\&SEED. In: Kleiman, J., Tagawa, M., Kimoto, Y. (eds.) Protection of materials and structures from the space environment, pp. 73-82. Springer, Heidelberg (2012). https://doi.org/10.1007/ 978-3-642-30229-9_6

20. Kimoto, Y., Fujita, T., Furuta, N., Kitamura, A., Suzuki, H.: Development of space-qualified photocurable-silsesquioxanecoated polyimide films. J. Spacecr. Rockets 53, 1028-1034 (2016). https://doi.org/10.2514/1.A33488

21. Brown, J.F., Jr., Vogt, L.H., Jr., Katchman, A., Eustance, J.W., Kiser, K.M., Krantz, K.W.: Double chain polymers of phenylsilsesquioxane. J. Am. Chem. Soc. 82, 6194-6195 (1960). https://doi.org/10.1021/ja01508a054

22. Baney, R.H., Itoh, M., Sakakibara, A., Suzuki, T.: Silsesquioxanes. Chem. Rev. 95, 1409-1430 (1995). https://doi.org/10. 1021/cr00037a012

23. Waki, M., Kimoto, Y.: Surface analysis results of atomic oxygen protective coating film. In: Proc. of 31st international symposium on space technology and science (2017)

24. Miyazaki, E., Tagawa, M., Yokota, K., Yokota, R., Kimoto, Y., Ishizawa, J.: Investigation into tolerance of polysiloxaneblock-polyimide film against atomic oxygen. Acta Astronaut. 66, 922-928 (2010). https://doi.org/10.1016/j.actaastro.2009. 09.002

25. Miyazaki, E., Kimoto, Y., Yokota, R.: Flight experiment results of the polysiloxane-block-polyimide "BSF-30" on the JEM/ MPAC\&SEED mission on the ISS. In: Kleiman, J., Tagawa, M., Kimoto, Y. (eds.) Protection of materials and structures from the space environment, pp. 295-302. Springer, Heidelberg (2012). https://doi.org/10.1007/978-3-642-30229-9_27

26. Yokota, K., Abe, S., Tagawa, M., Iwata, M., Miyazaki, E., Ishizawa, J., Kimoto, Y., Yokota, R.: Degradation property of commercially available Si-containing polyimide in simulated atomic oxygen environments for low earth orbit. High Perform. Polym. 22, 237-251 (2010). https://doi.org/10.1177/09540 08308101535

27. Fujimoto, Y., Kita, K., Okura, R., Iwata, M., Yokota, K., Tagawa, M.: A consideration of erosion mechanism of FEP/ $\mathrm{Ag}$ in sub-low earth orbit space environment. In: Proc. of the 14th spacecraft environment symposium JAXA-SP-17-006, pp. 53-57. (2018)

28. Finckenor, M.M., Golden, J.N., Kravchenko, M.: Analysis of international space station vehicle materials exposed on materials international space station experiment from 2001 to 2011. In: NASA technical publication 2013-217498 (2013)
29. Linton, R., Whitaker, A., Finckenor, M.: Space environment durability of beta cloth in LDEF thermal blankets. In: NASA conference paper N94-31015, pp. 31-45. (1993)

30. Mori, K., Miyazaki, E., Goto, A., Kimoto, Y.: Restore a flexibleOSR (Ag deposited PEI with cerium oxide) and evaluate degradation at space environment including on orbital exposure. In: Proc. of 62th space sciences and technology conference (2018)

31. ASTM: Solar constant and zero air mass solar spectral irradiance tables. ASTM Standard E490-00a (2014). https://doi.org/ 10.1520/e0490-00ar14

32. JAXA: JAXA Space Environment \& Effects System (SEES). http://seesweb.s.tksc.in-jaxa/English/Top/top_e.shtml

33. Joyce, A., D.: Low earth orbital atomic oxygen and ultraviolet radiation effects on polymers. In: NASA technical memorandum 103711 (1991)

34. Ohnishi, A., Sato, R.: Design of spacecraft thermal control materials on polyimide film. Trans. Inst. Eelctr. Eng. Jpn. 116, 136-142 (1996). https://doi.org/10.1541/ieejfms1990.116.2_ 136

35. Li, L., Yang, J.C., Minton, T.K.: morphological changes at a silver surface resulting from exposure to hyperthermal atomic oxygen. J. Phys. Chem. C 111, 6763-6771 (2007). https://doi. org/10.1021/jp0657843

36. Moore, W.M., Codella, P.J.: Oxidation of silver films by atomic oxygen. J. Phys. Chem. 92, 4421-4426 (1988). https://doi.org/ 10.1021/j100326a035

37. Yuqing, X., Liming, L., Weigang, L., Dequan, Y., Daoan, D.: Atomic force microscopy and X-ray photoelectron spectroscopy study on nanostructured silver thin films irradiated by atomic oxygen. Mater. Sci. Eng. B 79, 68-70 (2001). https://doi.org/ 10.1016/S0921-5107(00)00562-6

38. Chiu, Y., Rambabu, U., Hsu, M.-H., Shieh, H.-P.D., Chen, C.-Y., Lin, H.-H.: Fabrication and nonlinear optical properties of nanoparticle silver oxide films. J. Appl. Phys. 94, 1996-2001 (2003). https://doi.org/10.1063/1.1589178

39. Brunsvold, A.L., Minton, T.K., Gonzalez, R.: An investigation of the resistance of polyhedral oligomeric silsesquioxane polyimide to atomic-oxygen attack. High Perform. Polym. 16, 303-318 (2004). https://doi.org/10.1177/0954008304044121

40. Minton, T.K., Wright, M.E., Tomczak, S.J., Marquez, S.A., Shen, L., Brunsvold, A.L., Cooper, R., Zhang, J., Vij, V., Guenthner, A.J., Petteys, B.J.: Atomic oxygen effects on POSS polyimides in low earth orbit. ACS Appl. Mater. Interfaces 4, 492-502 (2012). https://doi.org/10.1021/am201509n

41. Gilman, J.W., Schlitzer, D.S., Lichtenhan, J.D.: Low earth orbit resistant siloxane copolymers. J. Appl. Polym. Sci. 60, 591-596 (1996). https://doi.org/10.1002/(SICI)1097-4628(19960425) 60:4\%3c591::AID-APP12\%3e3.0.CO;2-2

42. Fischer, H.R., Tempelaars, K., Kerpershoek, A., Dingemans, T., Iqbal, M., Lonkhuyzen, H., Iwanowsky, B., Semprimoschnig, C.: Development of flexible LEO-resistant PI films for space applications using a self-healing mechanism by surface-directed phase separation of block copolymers. ACS Appl Mater. Interaces 2, 2218-2225 (2010). https://doi.org/10.1021/am100223v

43. Lei, X., Qiao, M., Tian, L., Chen, Y., Zhang, Q.: Evolution of surface chemistry and morphology of hyperbranched polysiloxane polyimides in simulated atomic oxygen environment. Corros. Sci. 98, 560-572 (2015). https://doi.org/10.1016/j.corsci. 2015.05.060

44. Silverman, E.M.: Space environmental effects on spacecraft: LEO materials selection guide. In: NASA contractor report 4661 (1995)

45. Moulder, J.F., Stickle, W.F., Sobol, P.E., Bomben, K.D.: Handbook of X-ray photoelectron spectroscopy. Perkin-Elmer Corporation (1992) 
46. Hoflund, G.B., Gonzalez, R.I., Phillips, S.H.: In situ oxygen atom erosion study of a polyhedral oligomeric silsesquioxanepolyurethane copolymer. J. Adhes. Sci. Technol. 15, 1199-1211 (2001). https://doi.org/10.1163/156856101317048707

47. Qian, M., Murray, V.J., Wei, W., Marshall, B.C., Minton, T.K.: Resistance of POSS polyimide blends to hyperthermal atomic oxygen attack. ACS Appl. Mater. Interfaces 8, 33982-33992 (2016). https://doi.org/10.1021/acsami.6b10612

48. Wang, X., Li, Y., Qian, Y., Qi, H., Li, J., Sun, J.: Mechanically robust atomic oxygen-resistant coatings capable of autonomously healing damage in low earth orbit space environment. Adv. Mater. 30, 1803854 (2018). https://doi.org/10.1002/adma. 201803854

49. Tiwari, A., Gupta, M.K., Nema, S.K.: Effect of oxygen plasma asher on poly(methylphenylsiloxane)-polyimide blends. J. Mater. Sci. 39, 1695-1701 (2004)
50. Connell, J.W., Crivello, J.V., Bi, D.: Effect of low earth orbit atomic oxygen exposure on epoxy functionalized siloxanes. J. Appl. Polym. Sci. 57, 1251-1259 (1995). https://doi.org/10. 1023/B:JMSC.0000016172.09723.ee

51. Verker, R., Grossman, E., Eliaz, N.: Erosion of POSS-polyimide films under hypervelocity impact and atomic oxygen: the role of mechanical properties at elevated temperatures. Acta Mater. 57, 1112-1119 (2009). https://doi.org/10.1016/j.actamat.2008. 10.054

Publisher's Note Springer Nature remains neutral with regard to jurisdictional claims in published maps and institutional affiliations. 